\title{
Article \\ A Green Method of Extracting and Recovering Flavonoids from Acanthopanax senticosus Using Deep Eutectic Solvents
}

\author{
Xinyu Zhang $(\mathbb{D}$, Jianqing $S u *(\mathbb{D}$, Xiuling Chu *(D) and Xiaoya Wang \\ College of Agronomy, Liaocheng University, Liaocheng 252000, China; xinxinxinxinyuyuyu@163.com (X.Z.); \\ wangxy9625@163.com (X.W.) \\ * Correspondence: sujianqing@lcu.edu.cn (J.S.); chuxiul@163.com (X.C.); Tel.: +86-150-9503-9358 (J.S.); \\ $+86-150-2062-6235$ (X.C.)
}

check for updates

Citation: Zhang, X.; Su, J.; Chu, X.; Wang, X. A Green Method of Extracting and Recovering Flavonoids from Acanthopanax senticosus Using Deep Eutectic Solvents. Molecules 2022, 27, 923. https://doi.org/10.3390/molecules 27030923

Academic Editor: Giovanni D'Orazio

Received: 2 December 2021

Accepted: 24 January 2022

Published: 29 January 2022

Publisher's Note: MDPI stays neutral with regard to jurisdictional claims in published maps and institutional affiliations.

Copyright: (C) 2022 by the authors. Licensee MDPI, Basel, Switzerland. This article is an open access article distributed under the terms and conditions of the Creative Commons Attribution (CC BY) license (https:// creativecommons.org/licenses/by/ $4.0 /)$.

\begin{abstract}
In recent years, green extraction of bioactive compounds from herbal medicines has generated widespread interest. Deep eutectic solvents (DES) have widely replaced traditional organic solvents in the extraction process. In this study, the efficiencies of eight DESs in extracting flavonoids from Acanthopanax senticosus (AS) were compared. Response surface methodology (RSM) was employed to optimize the independent variable including ultrasonic power, water content, solidliquid ratio, extraction temperature, and extraction time. DES composed of glycerol and levulinic acid (1:1) was chosen as the most suitable extraction medium. Optimal conditions were ultrasonic power of $500 \mathrm{~W}$, water content of $28 \%$, solid-liquid ratio of $1: 18 \mathrm{~g} \cdot \mathrm{mL}^{-1}$, extraction temperature of $55^{\circ} \mathrm{C}$, and extraction time of $73 \mathrm{~min}$. The extraction yield of total flavonoids reached $23.928 \pm 0.071 \mathrm{mg} \cdot \mathrm{g}^{-1}$, which was $40.7 \%$ higher compared with ultrasonic-assisted ethanol extraction. Macroporous resin (D-101, HPD-600, S-8 and AB-8) was used to recover flavonoids from extracts. The AB-8 resin showed higher adsorption/desorption performance, with a recovery rate of total flavonoids of up to $71.56 \pm 0.256 \%$. In addition, DES solvent could efficiently be reused twice. In summary, ultrasonicassisted DES combined with the macroporous resin enrichment method is exceptionally effective in recovering flavonoids from AS, and provides a promising environmentally friendly and recyclable strategy for flavonoid extraction from natural plant sources.
\end{abstract}

Keywords: deep eutectic solvent; Acanthopanax senticosus; flavonoids; extraction; macroporous resins; recycle

\section{Introduction}

Acanthopanax senticosus, also known as Siberian ginseng in China, is widely distributed in Russia and Asia [1]. The plant has been traditionally used for nourishing the liver and kidney, strengthening muscles and bones, improving kidney function, and soothing the nerves [2]. All parts of the plant, including its roots, stems, leaves, flowers, and fruits, have pharmacological activities, and are often used as functional medicine [3]. Active ingredients of the plant components, such as flavonoids, have been shown to improve the body's innate immunity and antioxidant capacity [4,5], reduce myocardial cell damage [6], and enhance antibacterial efficacy [7], among other effects. AS flavonoids identified to date include hyperoside, quercetin, citrin, and rutin [8]. Conventional solvent extraction, using chemicals such as methanol, ethanol [9], and ethyl acetate, was previously used. However, organic solvents are expensive, flammable, toxic, and non-degradable, and their excessive use not only damages the natural environment, but also threatens human health [10]. Several non-toxic or less toxic alternatives have been explored, such as heterogeneous catalysts, supercritical fluids, and ionic liquids (ILS) [11]. Among them, ILs are composed of multiple components with characteristic ionic bonds formed between cations and anions. The extraction of flavonoids by this method has attracted attention, and it has the advantages of clean process and high extraction efficiency [12]. However, one notable limitation is 
that many ILs are based on imidazole and pyridine, and therefore exert toxic effects [13]. Therefore, a "green solvent" that is easy to operate, efficient, and consumes less energy for extraction of AS total flavonoids remains a critical requirement.

Eutectic solvents were initially synthesized in 2001 [14], and have been shown to possess similar physical and chemical properties as ILs. In 2011, the concept of "natural eutectic solvents" (NADES) was proposed. These solvents usually contain secondary metabolites, such as sugar alcohols, sugars, amino acids, and organic acids, as NADES components. Traditional ionic liquids are mostly prepared through ion exchange or neutralization reactions, which involve issues such as complex preparation, high cost, and difficulty in purification, and the toxicity of pyridine and imidazole ionic liquids is even comparable to that of traditional organic solvents. NADES has a single component, and its application in extraction is greatly restricted, thus people pay more attention to the research of DES. DESs are liquids usually formed by hydrogen bond acceptors (HBA, salts such as quaternary ammonium salts) and hydrogen bond donors (HBD, such as polyols, urea, and carboxylic acids) $[15,16]$. As an extraction solvent, DES has the advantages of higher efficiency, shorter time, lower cost, no toxicity, biodegradability, and improved product purity [17], offering a wide range of application prospects [18-21]. Accordingly, determination of the utility of different DES types for extraction of active ingredients of Chinese herbal medicines has become a popular research direction. At present, DES-based methods have been extensively explored for abstraction of flavonoids from traditional Chinese medicines [22-25]. Zhao et al. [26] used choline chloride (ChCl)-ethylene glycol (Eg) (1:4) DES to extract rutin from Sophora japonica under the condition of $20 \%$ water content, and the extraction rate was as high as $194.17 \pm 2.31 \mathrm{mg} \cdot \mathrm{g}^{-1}$. Compared with $60 \%$ ethanol and $60 \%$ methanol, it has obvious advantages. Duan et al. [27] prepared betaine-malic acid (Ma) (1:1), L-proline-levulinic acid (La) (1:2), and choline chloride- $N, N^{\prime}$-dimethylurea (1:1) from 14 kinds of DESs. They were used to extract icariin, and the results all showed that the extraction rate was higher than that of the methanol method. In order to extract baicalin from Scutellaria baicalensis Georgi, Wang et al. [28] prepared choline chloride-lactic acid (LA) DES with a molar ratio of 1:2. The results showed that the extraction rate of baicalin with DES combined with ultra-high-pressure extraction was $116.8 \mathrm{mg} \cdot \mathrm{g}^{-1}$, which was higher than that of $70 \%$ ethanol and heat reflux method. Until now, the research on DESs used to extract flavonoids from AS has not been explored.

In this study, an ultrasonic-assisted DES extraction method was introduced and, for the first time, tailor-made DESs were used to extract flavonoids from AS. The feasibility and effectiveness of eight DES in AS flavonoid separation were evaluated. The Box-Behnken design (BBD)-response surface method (RSM) was used to optimize extraction conditions. Furthermore, macroporous resins was used to recover total flavonoids from DESs extracts and the recovered DESs was evaluated on the recycling utility. The procedure developed in this study provides a solid theoretical foundation for efficient and rapid extraction of flavonoids from AS.

\section{Results}

\subsection{Determination of Total Flavonoids Content}

The total flavonoids content of the AS extract was calculated the calibration curve as follows: $y=0.0066 x-0.0391, R^{2}=0.9942$. The rutin reference solution displayed a good linear relationship within a concentration range of 0 to $1.5 \mathrm{mg} \cdot \mathrm{mL}^{-1}$.

\subsection{Physical and Chemical Properties of DESs}

The physical and chemical properties of DESs, such as density, melting point, conductivity, acidity and alkalinity, viscosity, and polarity, depend on their composition [29]. Analysis of these properties should facilitate effective extraction of target compounds from natural materials. The presence of phenolic hydroxyl groups in flavonoids makes them acidic [30]. Consequently, flavonoids are more stable under acidic conditions and easily soluble in polar solvents [31]. Earlier findings suggest that the extraction efficiency of alcohol 
and amine-based DESs for flavonoids is higher than that of sugar and acid DESs [32,33]. Due to the higher viscosity of the latter group, it is not conducive to the flow of the medium. In the current study, three types of DESs were selected for extraction of AS total flavonoids, specifically choline chloride, glycerol (Gly), and organic acids. Among them, the choline chloride in choline chloride DESs acts as hydrogen bond acceptor, the glycerol in glycerol DESs acts as hydrogen bond donor, and a series of organic acids in organic acid DESs act as hydrogen bond acceptors. Choline chloride $\left(\mathrm{C}_{5} \mathrm{H}_{14} \mathrm{ClNO}\right)$ is a white crystal at room temperature with an electron-deficient center of a nitrogen positive ion and generally used as a hydrogen bond acceptor. Based on earlier reports [15,34], we used $\mathrm{ChCl}$ as the hydrogen bond acceptor and ethylene glycol, levulinic acid, and 1,4-butanediol (Buta) as hydrogen bond donors, and prepared DESs at a range of molar ratios. Glycerol, also known as glycerin $\left(\mathrm{C}_{3} \mathrm{H}_{8} \mathrm{O}_{3}\right)$, is a viscous liquid at room temperature. Due to the presence of three hydroxyl groups, the molecule has good capacity as a hydrogen bond supplier and is generally used as a hydrogen bond donor. With reference to extensive earlier research, Gly was used as the basic part and La, lactic acid, and malic acid added as hydrogen bond acceptors. Due to the lower viscosity of Gly, the viscosity of this type of DES is expected to be lower. The organic acid, $\mathrm{La}$, is in a translucent crystalline state at room temperature. Citric acid (Ca) is 2-hydroxypropane-1,2,3-tricarboxylic acid in liquid form. Owing to the presence of more than one carboxyl group, Ca shows strong ability to accept hydrogen bond. Therefore, Buta and Gly were selected as hydrogen bond donors for DES preparation. The $\mathrm{pH}$ and viscosity of individual DESs were measured at $30^{\circ} \mathrm{C}$ (Table 1). Among the eight DESs under investigation, Gly DESs have stronger acidity, and DES-4 and DES-7 showed lowest viscosity [35]. Furthermore, although DES-6 has the strongest $\mathrm{pH}$, but its viscosity is at a medium level; it also exhibits a strong extraction effect. In addition, DES-8 has low viscosity and strong acidity, but it still does not show good extraction ability. This may be because $\mathrm{Ca}$, as a hydrogen bond acceptor, has a weaker ability to accept hydrogen bonds due to its lower polarity. The interaction force formed between Ca and Gly is small, and it is difficult to achieve effective extraction of target components. The collective data (Table 1 and Figure 1) clearly indicate that physical and chemical properties of DESs are important factors affecting extraction capacity, and it is not only affected by one property.

Table 1. Physical and chemical properties of deep eutectic solvents.

\begin{tabular}{cccccc}
\hline \multirow{2}{*}{ Serial Number } & HBA & HBD & pH & Viscosity/mPa·s \\
\cline { 4 - 6 } & & & Molar Ratio & DH & 26.00 \\
DES-1 & ChCl & Eg & $1: 2$ & 4.40 & 119.00 \\
DES-2 & ChCl & La & $1: 2$ & 1.40 & 47.00 \\
DES-3 & ChCl & Buta & $1: 3$ & 3.74 & 12.00 \\
DES-4 & La & Gly & $1: 1$ & 1.85 & 21.00 \\
DES-5 & LA & Gly & $1: 1$ & 1.86 & 45.39 \\
DES-6 & Ma & Gly & $1: 1$ & 1.03 & 9.65 \\
DES-7 & La & Buta & $2: 1$ & 2.25 & 64.01 \\
DES-8 & Ca & Gly & $1: 2$ & 1.06 & \\
\hline
\end{tabular}

\subsection{Selection of DESs}

We conducted a pre-experiment on Soxhlet and Batch, and the results verified the conjecture that the extraction rates of both were lower than those of UA-DES method. Thus, we directly compared the effects of eight types of DES (water content of $30 \%$, solid-liquid ratio of $\left.1: 20 \mathrm{~g} \cdot \mathrm{mL}^{-1}\right)$ under ultrasonic heating (UA) $\left(40 \mathrm{kHz} ; 500 \mathrm{~W} ; 40{ }^{\circ} \mathrm{C} ; 20 \mathrm{~min}\right)$. The results are shown in Figure 1. Overall, three DESs (DES-4, DES-6 and DES-7) had high extraction rates, while the extraction effects of DES- 5 and DES- 8 were extremely poor. In general, the flavonoid extraction rate of Gly DESs was higher than that of the other two types of DESs, and at a Gly and La molar ratio of 1:1, the extraction rate was the highest, yielding $16.377 \pm 0.177 \mathrm{mg} \cdot \mathrm{g}^{-1}$, which was significantly greater compared with other DES types $(p<0.0001)$. This finding may be attributable to the low viscosity of the DES 
system composed of Gly and La, which can lead to high flow and diffusion, promoting suspension and dispersion of AS powder in the solvent and increasing the contact area, which is beneficial for total flavonoid extraction. Accordingly, DES composed of Gly and La was selected as the optimal extractant and total flavonoids of AS were extracted with ultrasonic assistance. A single factor experiment was subsequently designed to optimize the extraction parameters.

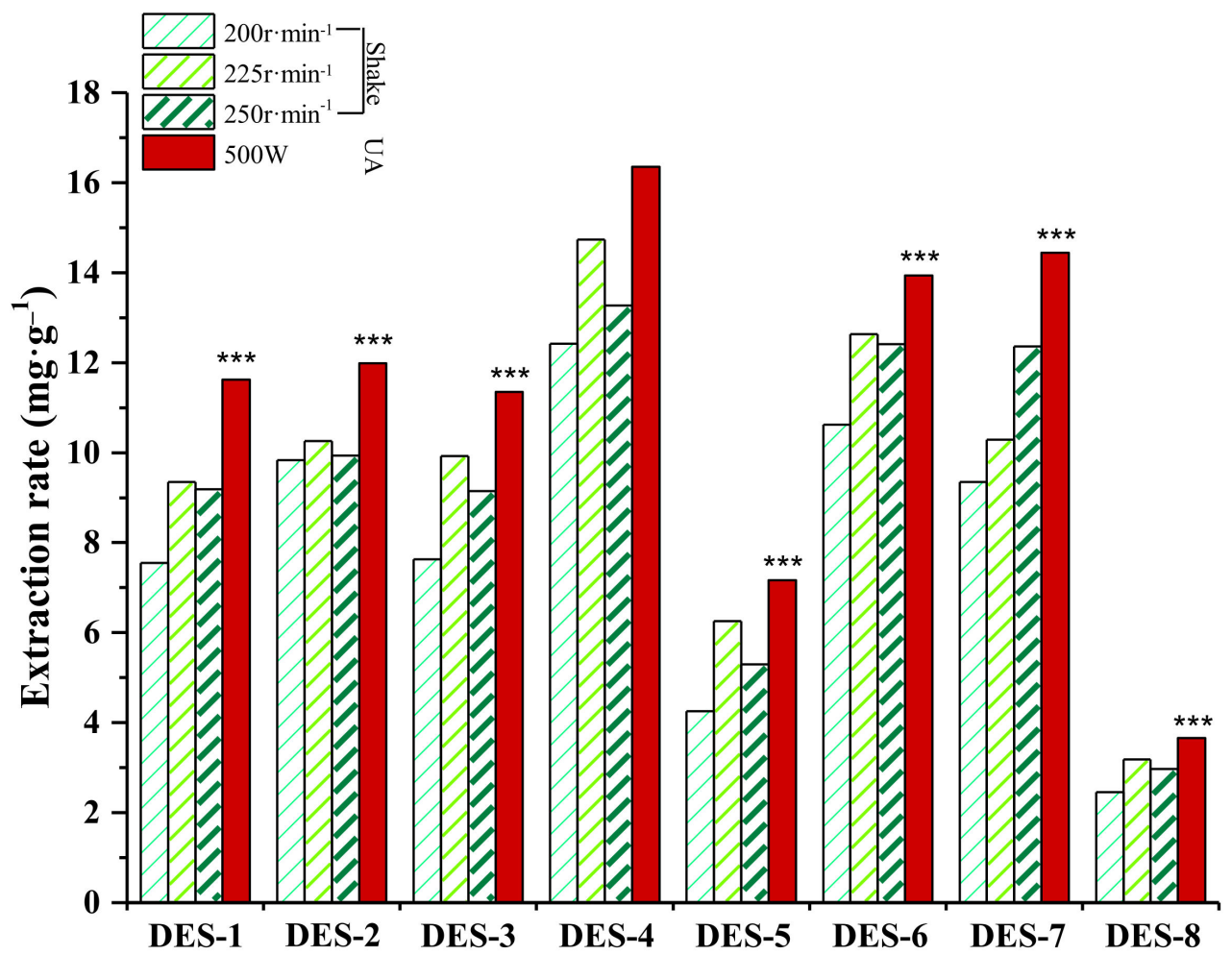

Figure 1. Effects of auxiliary operation on the extraction rates of total AS flavonoids. Note: Values represent mean $\pm \mathrm{SD}$ of three independent experiments (compared with the extraction rate of DES-4; *** $p<0.0001)$.

\subsection{Fourier-Transform Infrared Spectroscopy (FT-IR) Analysis of Gly-La DES}

In this experiment, levulinic acid was used as the starting HBA combined with glycerol to form a hydrophilic DES [36], and weakly polar flavonoids were extracted. The establishment of hydrogen bonds between two compounds was responsible for the formation of eutectic mixtures. Comparison of the FT-IR spectra of glycerin, levulinic acid and optimal solvent (Gly-La) revealed overlapping spectra of glycerin, levulinic acid and DES, as shown in Figure 2. The FT-IR spectrum has two regions, specifically, fingerprint $\left(1333-400 \mathrm{~cm}^{-1}\right)$ and functional $\left(4000-1333 \mathrm{~cm}^{-1}\right)$ groups. The FT-IR spectrum of Gly-La showed a shift in the $\mathrm{OH}$ band of glycerol from $3281.62 \mathrm{~cm}^{-1}$ to $3368.28 \mathrm{~cm}^{-1}$ and a strong broad peak at $3500-3200 \mathrm{~cm}^{-1}$, and the intrinsic frequency of the hydroxyls appeared at $3700-3000 \mathrm{~cm}^{-1}$. Corresponding to $\mathrm{OH}$ vibration, indicating the formation of a large number of DES. For the hydrogen bond in the infrared spectrum of $2800-2950 \mathrm{~cm}^{-1}$, a wider band was observed, indicating the existence of a strong $-\mathrm{OH}-\mathrm{O}^{-}$interaction [37], where the formation of hydrogen bonds considers the combination of the carbonyl group and carboxyl group in La with the hydroxyl group in Gly. This meant that the peaks at $3368.28 \mathrm{~cm}^{-1}$ and $2936.82 \mathrm{~cm}^{-1}$ in FT-IR spectra (Gly-La) contained hydrogen bonds. The carbonyl band of levulinic acid expanded from $1700.00 \mathrm{~cm}^{-1}$ and transferred to the high wave value of $1703.69 \mathrm{~cm}^{-1}$ in Gly-La. The strong peak corresponded to the stretching vibration of carbon oxide in the polymer (mainly $\mathrm{C}=\mathrm{C}$ and $\mathrm{C}=0$ ). FT-IR spectra of glycerol and levulinic acid contained absorption peaks at $1028.84 \mathrm{~cm}^{-1}$ and $1158.70 \mathrm{~cm}^{-1}$, respectively, that shifted to 
$1038.23 \mathrm{~cm}^{-1}$ and $1164.77 \mathrm{~cm}^{-1}$ in the spectrum of Gly-La, which was related to expansion and contraction of single bonds. Vibration (mainly C-C, C-O, C-N) is closely related, since hydrogen bond formation leads to changes in the bond electron density, subsequent frequency of the stretching vibration, and ultimately, the spectrum. The above results provide theoretical support for the efficient extraction of target components using the Gly-La DES system. In addition, during infrared spectrum detection, $\mathrm{CO}_{2}$ background was deducted from all samples, therefore the influence of $\mathrm{CO}_{2}$ on infrared spectrum detection results was no longer considered.

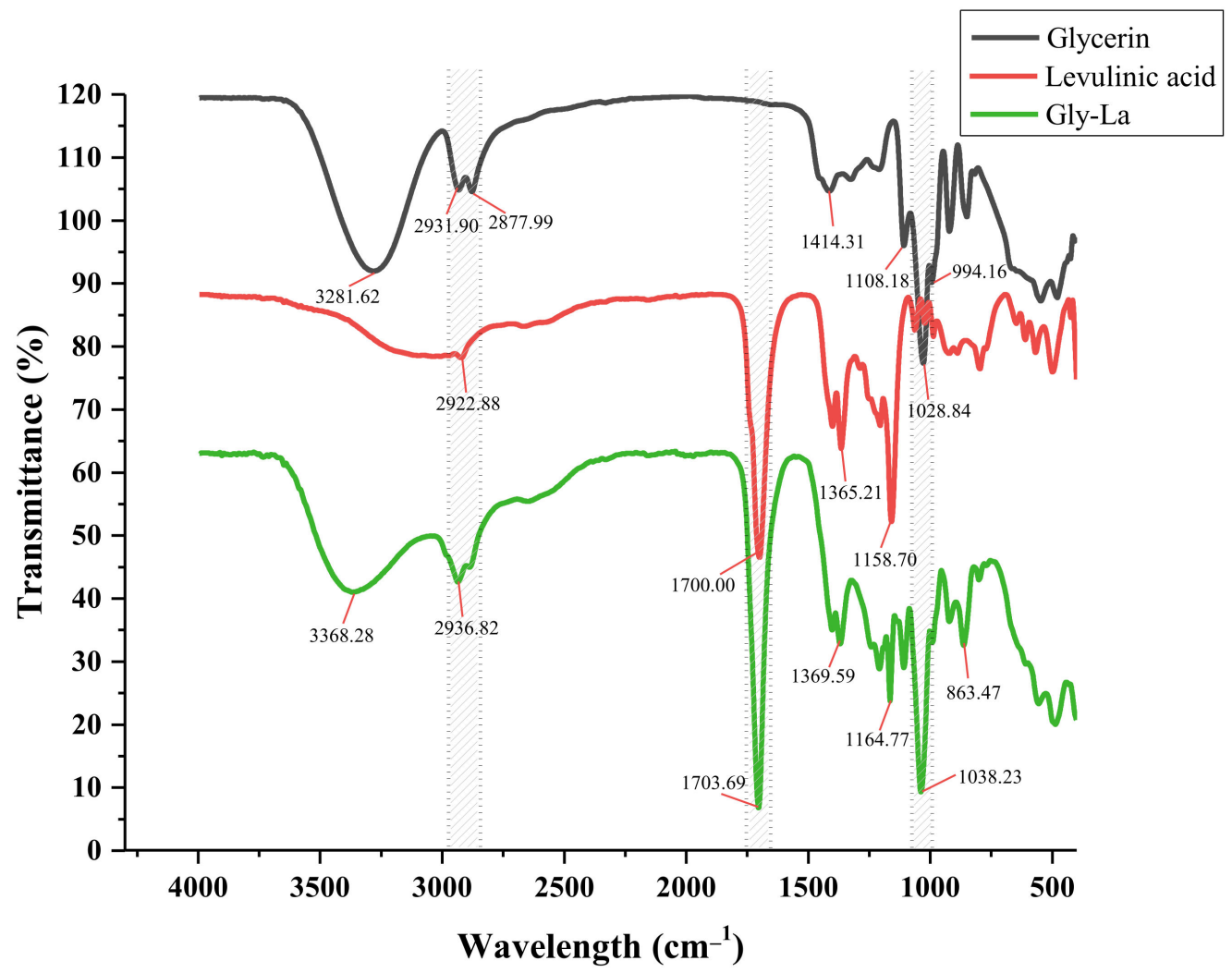

Figure 2. FT-IR spectra of glycerin, levulinic acid and Gly-La.

\subsection{Selection of the Most Suitable Ultrasonic Power Level}

At an ultrasonic power of $500 \mathrm{~W}$, the flavonoid yield was the largest (Figure 3). Upon an increase in ultrasonic power from $200 \mathrm{~W}$ to $500 \mathrm{~W}$, the flavonoid yield was increased. With greater ultrasonic power, the molecular vibration speed was faster and intermolecular interactions strengthened, which promoted dissolution of flavonoids. In addition, with increasing temperature, the viscosity of the eutectic solvent was decreased and AS powder was more fully dissolved and dispersed, leading to more efficient extraction of flavonoids [38]. However, under conditions of continual increase in ultrasonic power, the yield of flavonoids was significantly decreased. One possible explanation is that highfrequency vibrations affect the network structure formed within DESs, leading to instability, and a strong cavitation effect degrades flavonoids and other components, thereby reducing the ability to extract flavonoids from AS. Accordingly, the ultrasonic power was set as $500 \mathrm{~W}$.

\subsection{Determination of the Optimal $H B A-H B D$ Ratio}

Most DESs are in liquid state at room temperature and their melting points are lower than any other component of the solvent [39]. The melting point mainly depends on interactions between the hydrogen bond acceptor and donor. Increased force is associated with greater degree of damage to the crystal structure and lower melting point of DESs [40]. Dur- 
ing the preparation process, the melting point is mainly affected by the molar ratio between the hydrogen bond acceptor and donor [41]. The appropriate molar ratio is correlated with lower melting point and larger operating temperature range during the extraction process, which is more conducive to transmission of the medium. Therefore, optimization of the HBA-HBD ratio is crucial to improve the extraction rate of total flavonoids. In this study, Gly and La were used to formulate eutectic solvents under fixed conditions at a range of molar ratios (2:1, 1.5:1, 1:1, 1:1.5, and 1:2). The extraction rates of AS total flavonoids were measured (Figure 3). As the ratio of Gly-La gradually decreased, the extraction rate of total flavonoids initially increased and subsequently decreased. The extraction rate was significantly higher at a molar ratio of $1: 1\left(16.255 \pm 0.313 \mathrm{mg} \cdot \mathrm{g}^{-1}\right)$ relative to the other molar ratios tested $(p<0.0001)$. The reason for this finding may be that reduction in the Gly content leads to decreased viscosity and surface tension of the deep eutectic solvent, thereby improving the diffusion and mass transfer effect [42]. Moreover, La is acidic. The partial acidic environment is beneficial for extraction of flavonoids, and therefore, the extraction efficiency increases with decreasing HBA-HBD ratio. However, excessive acid or alkali induce significant changes in the physicochemical properties of DES, such as $\mathrm{pH}$, polarity, viscosity, and density, which can reduce extraction efficiency. Based on the results, a Gly-La ratio of 1:1 was selected for follow-up experiments.

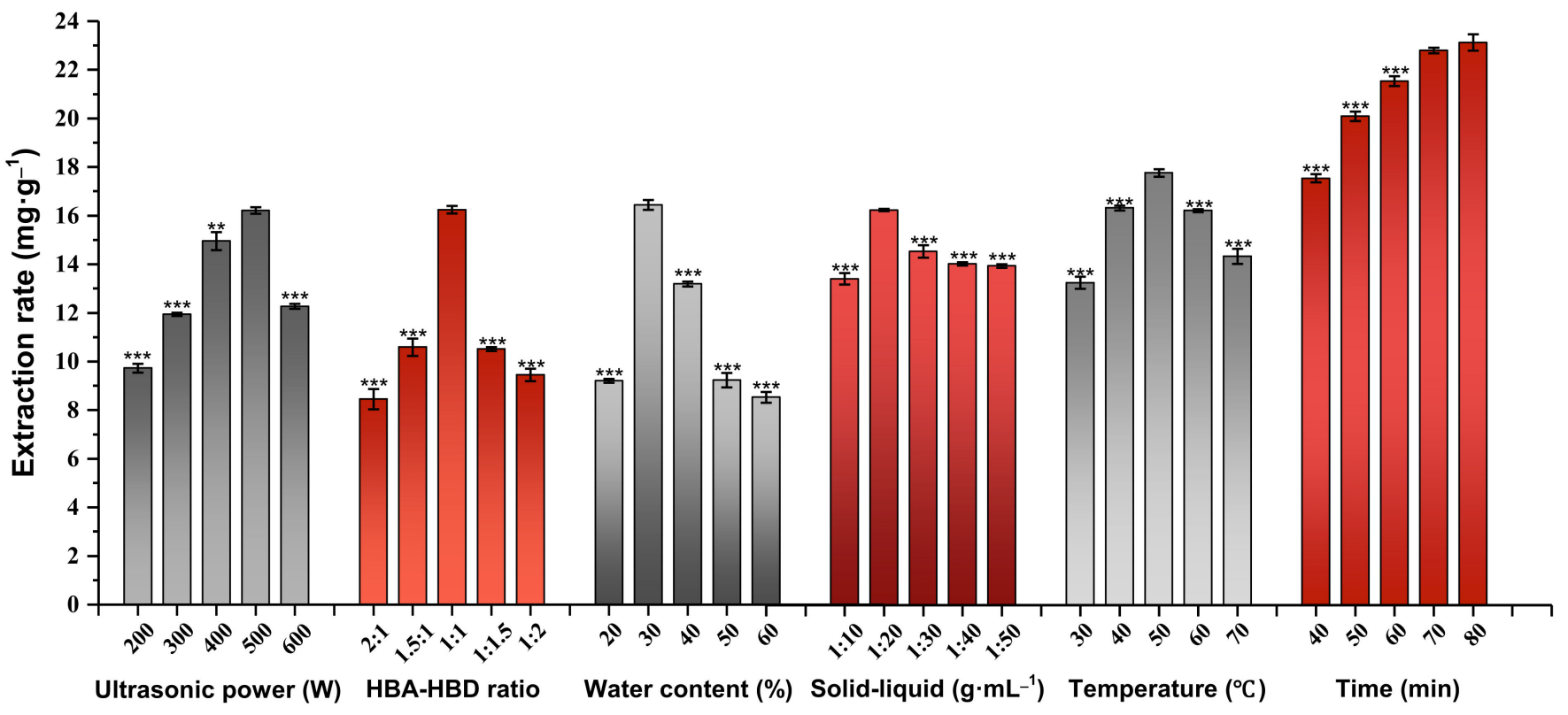

Figure 3. Effects of ultrasonic power (W), HBA-HBD ratio, water content (\%), solid-liquid ratio $\left(\mathrm{g} \cdot \mathrm{mL}^{-1}\right)$, extraction temperature $\left({ }^{\circ} \mathrm{C}\right)$, and extraction time $(\mathrm{min})$ on the extraction rate of total flavonoids from AS. Note: Values represent mean \pm SD of three independent experiments (compared with the highest extraction rate under optimal conditions in each group; ${ }^{* *} p<0.01$ and ${ }^{* * *} p<0.0001$ ).

\subsection{Selection of the Most Suitable Water Content}

Due to the large number of network structures composed of hydrogen bond donors and acceptors, van der Waals forces and other electrostatic interactions, the majority of DESs have relatively high viscosity at room temperature [43], thereby affecting the intermolecular interactions of the extracted liquid. Optimization of the fluidity of DESs plays a key role in improving the extraction rate [44]. Viscosity is not only related to the HBA-HBD ratio, but also the water content of DESs [45]. Accordingly, we further focused on the influence of different water contents on DES extraction capability (Figure 3). Upon increasing the water content of DESs from $20 \%$ to $60 \%$, the extraction rate of total flavonoids was significantly altered, initially showing an increase followed by a decrease, with peak levels recorded at a water content of $30 \%$. One possibility is that the addition of a small amount of water reduces DES viscosity, but also maintains their structure [46], thereby increasing the contact 
area between the drug and extractant, which facilitates dissolution of the target component. In addition, according to the principle of "similar compatibility" [47], water as a strong polar solvent increases the dipole/polarizability of DES and is therefore closer to the polarity of flavonoids. However, the extended dilution of DES with water will result in the loss of existing hydrogen bonds. Since polar water molecules are very flexible and easy to form hydrogen bonds with other solvents, excess water molecules will form hydrogen bonds with the carbonyl and carboxyl of La, and will form hydrogen bonds with the hydroxyl of Gly, therefore the number of hydrogen bonds between La and Gly in DES will naturally reduce. In other words, the addition of excessive water causes competition with groups in the two solvents to form hydrogen bonds, resulting in the reduction or even disappearance of DES special structures [48], and ultimately weakens interactions between DESs and the target components. Therefore, in follow-up experiments, a DES system with a water content of $30 \%$ was selected for further optimization.

\subsection{Determination of the Optimal Solid-Liquid Ratio}

With the increase of solid-liquid ratio of DES, the extraction rate of AS total flavonoids initially increased and subsequently decreased. At an increased solid-liquid ratio of $1: 20 \mathrm{~g} \cdot \mathrm{mL}^{-1}$, the extraction rate reached a peak value of $16.259 \pm 0.257 \mathrm{mg} \cdot \mathrm{g}^{-1}$. Under the condition of solid-liquid ratio of $1: 20 \mathrm{~g} \cdot \mathrm{mL}^{-1}$, the value of flavonoid content is higher than that of other groups $(p<0.0001)$, as shown in Figure 3. This finding may be explained by the fact that as the material-liquid ratio gradually decreases, full contact between the material and solvent is achieved and the solution mass transfer driving force enhanced, which is beneficial for dissolution of flavonoids. At a ratio of $>1: 20 \mathrm{~g} \cdot \mathrm{mL}^{-1}$, simply increasing the solvent ratio leads to a decrease in total flavonoid yield, possibly since diluted solvent will increase the energy consumption of ultrasound, resulting in ineffective breakdown of cells. The effect of ultrasonic cavitation becomes less pronounced and, consequently, release of effective substances is reduced. At a solid-liquid ratio of $1: 20 \mathrm{~g} \cdot \mathrm{mL}^{-1}$, not only is the extraction effect optimal, but also the experimental costs are saved. Therefore, 1:20 $\mathrm{g} \cdot \mathrm{mL}^{-1}$ was selected to further optimize the extraction process.

\subsection{Selection of the Suitable Extraction Temperature}

Temperature is an important factor affecting various physical and chemical properties and functions of DESs [49]. With increasing temperature, the conductivity of DESs is elevated, along with a decrease in the surface tension [50]. As shown in Figure 3, as the extraction temperature gradually increased to $50{ }^{\circ} \mathrm{C}$, the extraction rate of total flavonoids reached a peak. Above this temperature, the extraction rate of total flavonoids showed a downward trend. This finding may be explained by the possibility that increase in temperature of the extraction medium speeds up molecular movement and reduces solvent viscosity, thereby increasing the solubility of the compound and energy of DESs, leading to enhanced mass transfer rate. However, excessive temperature also accelerates the dissolution of flavonoids and other active ingredients, ultimately resulting in decreased extraction rates. Therefore, an extraction temperature of $50{ }^{\circ} \mathrm{C}$ was selected for subsequent experiments.

\subsection{Selection of the Optimal Extraction Time}

Extraction time is another important parameter influencing the extraction rate of AS total flavonoids. In our experiments, when the ultrasound time was increased from $40 \mathrm{~min}$ to $70 \mathrm{~min}$, the extraction rate of total flavonoids was significantly increased and became stable with extended time (Figure 3). A potential explanation for this result is that the dissolution rate of the target component increases with time, but when osmotic pressure of the total solution system reaches equilibrium, mass transfer equilibrium between the DES system and AS powder is also reached. Moreover, long-term ultrasound leads to instability of the dissolved flavonoids. In addition, the excessively long ultrasound time was associated with significantly increased extraction costs. Ultimately, 70 min was selected as the extraction time for further optimization. 
In addition, we consider levulinic acid is more acidic, and $\mathrm{CO}_{2}$ is less acidic, thus $\mathrm{CO}_{2}$ in the air is generally difficult to actively dissolve in DES composed of levulinic acid. In addition, we believe that even if Gly-La DES absorbs trace amounts of $\mathrm{CO}_{2}$, this will not affect the results of its ability to extract traditional Chinese medicine. Therefore, the $\mathrm{CO}_{2}$ factor was excluded when designing the single factor test.

\subsection{RSM Optimization Test Data and Analysis}

\subsubsection{RSM Optimization Test}

On the basis of the single factor test and the Box-Behnken design principle, a fourfactor, three-level response surface test was designed to optimize the extraction process of AS total flavonoids. The water content of $\operatorname{DES}(\mathrm{A}, \mathrm{mL})$, solid-liquid ratio $\left(\mathrm{B}, \mathrm{g} \cdot \mathrm{mL}^{-1}\right)$, extraction temperature $\left(\mathrm{C},{ }^{\circ} \mathrm{C}\right)$, and extraction time $(\mathrm{D}, \mathrm{min})$ were taken as independent variables, with the extraction rate of total flavonoids $\left(\mathrm{Y}, \mathrm{mg} \cdot \mathrm{g}^{-1}\right)$ as the response variable of 29 groups. The results are presented in Table 2. Using Design Expert 13 software to perform quadratic regression fitting on data in Table 3, a regression model was obtained as follows:

Table 2. Response surface optimization of investigated variables using DES-4 as extraction solvent.

\begin{tabular}{|c|c|c|c|c|c|}
\hline Run & A Water Content (\%) & $\begin{array}{l}\text { B Solid-Liquid } \\
\text { Ratio (g/mL) }\end{array}$ & $\begin{array}{c}\text { C Extraction } \\
\text { Temperature }\left({ }^{\circ} \mathrm{C}\right)\end{array}$ & $\begin{array}{l}\text { D Extraction Time } \\
(\text { min) }\end{array}$ & Extraction Rate $(\mathrm{mg} / \mathrm{g})$ \\
\hline 1 & 0 & 0 & -1 & -1 & 16.953 \\
\hline 2 & -1 & 0 & -1 & 0 & 19.815 \\
\hline 3 & 1 & 1 & 0 & 0 & 20.963 \\
\hline 4 & 0 & -1 & 1 & 0 & 22.500 \\
\hline 5 & -1 & 0 & 1 & 0 & 21.647 \\
\hline 6 & -1 & -1 & 0 & 0 & 20.85 \\
\hline 7 & 0 & 0 & 1 & -1 & 20.502 \\
\hline 8 & 0 & 0 & 0 & 0 & 22.089 \\
\hline 9 & 0 & 0 & 0 & 0 & 22.667 \\
\hline 10 & 1 & 0 & -1 & 0 & 17.754 \\
\hline 11 & 1 & 0 & 0 & 1 & 20.502 \\
\hline 12 & 0 & 1 & -1 & 0 & 19.202 \\
\hline 13 & 0 & -1 & 0 & -1 & 17.700 \\
\hline 14 & -1 & 0 & 0 & 1 & 19.929 \\
\hline 15 & 0 & -1 & 0 & 1 & 21.700 \\
\hline 16 & 1 & 0 & 0 & -1 & 15.863 \\
\hline 17 & 0 & 1 & 0 & -1 & 21.317 \\
\hline 18 & 1 & 0 & 1 & 0 & 19.472 \\
\hline 19 & 0 & 0 & -1 & 1 & 18.212 \\
\hline 20 & 0 & -1 & -1 & 0 & 17.694 \\
\hline 21 & 0 & 0 & 0 & 0 & 22.844 \\
\hline 22 & 0 & 0 & 0 & 0 & 22.817 \\
\hline 23 & 0 & 0 & 0 & 0 & 23.418 \\
\hline 24 & 0 & 1 & 1 & 0 & 20.301 \\
\hline 25 & -1 & 1 & 0 & 0 & 22.68 \\
\hline 26 & -1 & 0 & 0 & -1 & 20.846 \\
\hline 27 & 0 & 0 & 1 & 1 & 22.843 \\
\hline 28 & 0 & 1 & 0 & 1 & 21.135 \\
\hline 29 & 1 & -1 & 0 & 0 & 19.412 \\
\hline
\end{tabular}

$\mathrm{Y}=22.77-0.9834 \mathrm{~A}+0.4785 \mathrm{~B}+1.47 \mathrm{C}+0.9283 \mathrm{D}-0.0697 \mathrm{AB}-0.0285 \mathrm{AC}+1.39 \mathrm{AD}$ $-0.9268 \mathrm{BC}-1.05 \mathrm{BD}+0.2705 \mathrm{CD}-1.41 \mathrm{~A}^{2}-0.6931 \mathrm{~B}^{2}-1.76 \mathrm{C}^{2}-1.69 \mathrm{D}^{2}$

Analysis of variance of data collated in Table 2 was conducted (presented in Table 3). The model F value was $12.40(p<0.0001)$. The $p$ value of the lack-of-fit item was not significant at 0.1293 , indicating that the equation is similar to actual data, which supports the utility of the combination. The model was selected to design the experiment for optimizing the extraction conditions of total flavonoids. The multiple correlation coefficient $\mathrm{R}^{2}$ value was 0.9254 , indicating that this model accurately reflects the correlations between 
the four factors and the total flavonoid extraction rate. The adjusted $R^{2}\left(\operatorname{Radj}^{2}=0.8507\right)$ value shows that the generated model is reasonable, and that only $0.1 \%$ of the response changes are due to unpredictable variables. In addition, the model displays better predictive ability $\left(\right.$ Rpred $\left.^{2}=0.6038\right)$. According to the significance standard, the effects of primary terms $A$ and $\mathrm{D}$, interaction term $\mathrm{AD}$, and quadratic term $\mathrm{A}^{2}$ on the extraction rate of $\mathrm{AS}$ total flavonoids reached a significant level $(p<0.01)$, along with the interaction terms $B C$ and $\mathrm{BD}$ and quadratic term $\mathrm{B}^{2}(p<0.05)$. According to the $\mathrm{F}$ value, the order of the degree of influence of each factor on the extraction rate of total flavonoids was determined as: extraction temperature $>$ water content $>$ extraction time $>$ solid-liquid ratio.

Table 3. ANOVA of the regression model for extraction efficiency of flavonoids. Note: Values represent mean $\pm \mathrm{SD}$ of three independent experiments (compared with the highest extraction rate under optimal conditions in each group; ${ }^{*} p<0.05^{* *} p<0.01$ and $\left.{ }^{* *} p<0.0001\right)$.

\begin{tabular}{|c|c|c|c|c|c|c|}
\hline Source & Sum of Squares & df & Mean Square & F-Value & $p$-Value & Significance \\
\hline Model & 104.04 & 14 & 7.43 & 12.4 & $<0.0001$ & significant \\
\hline A & 11.61 & 1 & 11.61 & 19.36 & 0.0006 & $* *$ \\
\hline B & 2.75 & 1 & 2.75 & 4.58 & 0.0504 & \\
\hline $\mathrm{C}$ & 25.92 & 1 & 25.92 & 43.24 & $<0.0001$ & $* * *$ \\
\hline $\mathrm{D}$ & 10.34 & 1 & 10.34 & 17.25 & 0.001 & $* *$ \\
\hline $\mathrm{AB}$ & 0.0195 & 1 & 0.0195 & 0.0325 & 0.8596 & \\
\hline $\mathrm{AC}$ & 0.0032 & 1 & 0.0032 & 0.0054 & 0.9424 & \\
\hline $\mathrm{AD}$ & 7.72 & 1 & 7.72 & 12.88 & 0.003 & $* *$ \\
\hline $\mathrm{BC}$ & 3.44 & 1 & 3.44 & 5.73 & 0.0312 & $*$ \\
\hline $\mathrm{BD}$ & 4.37 & 1 & 4.37 & 7.29 & 0.0172 & * \\
\hline CD & 0.2927 & 1 & 0.2927 & 0.4883 & 0.4961 & \\
\hline $\mathrm{A}^{2}$ & 12.86 & 1 & 12.86 & 21.46 & 0.0004 & $* *$ \\
\hline $\mathrm{B}^{2}$ & 3.12 & 1 & 3.12 & 5.2 & 0.0388 & $*$ \\
\hline$C^{2}$ & 20.16 & 1 & 20.16 & 33.63 & $<0.0001$ & $* * *$ \\
\hline $\mathrm{D}^{2}$ & 18.46 & 1 & 18.46 & 30.8 & $<0.0001$ & $* * *$ \\
\hline Residual & 8.39 & 14 & 0.5994 & & & \\
\hline Lack of Fit & 7.49 & 10 & 0.749 & 3.32 & 0.1293 & not significant \\
\hline Pure Error & 0.9019 & 4 & 0.2255 & & & \\
\hline Cor Total & 112.43 & 28 & & & & \\
\hline R-Squared & 0.9254 & & & & & \\
\hline Adj R-Squared & 0.8507 & & & & & \\
\hline Pred R-Squared & 0.6038 & & & & & \\
\hline Adeq Precision & 11.4871 & & & & & \\
\hline
\end{tabular}

\subsubsection{Analysis of the Response Surface Plot}

Specific software was applied to perform quadratic multivariate fitting for obtaining a three-dimensional curve diagram (above) and corresponding contour diagram (below), which intuitively reflect the trend and extent of the interactions between various factors and their effects on the total flavonoid extraction rate $(\mathrm{Y})$, as shown in Figure 4. The surface inclination of the response surface was positively correlated with interactions between the two factors. A larger surface slope (the greater the slope of the surface, the steeper the slope) signifies that the response value is more sensitive to factor changes, i.e., greater influence of factors on extraction rate of total flavonoids, and a smoother surface slope is indicative of a smaller influence. Elliptical contour lines indicate significant interactions between two factors while round contour lines correspond to low significance [51]. 

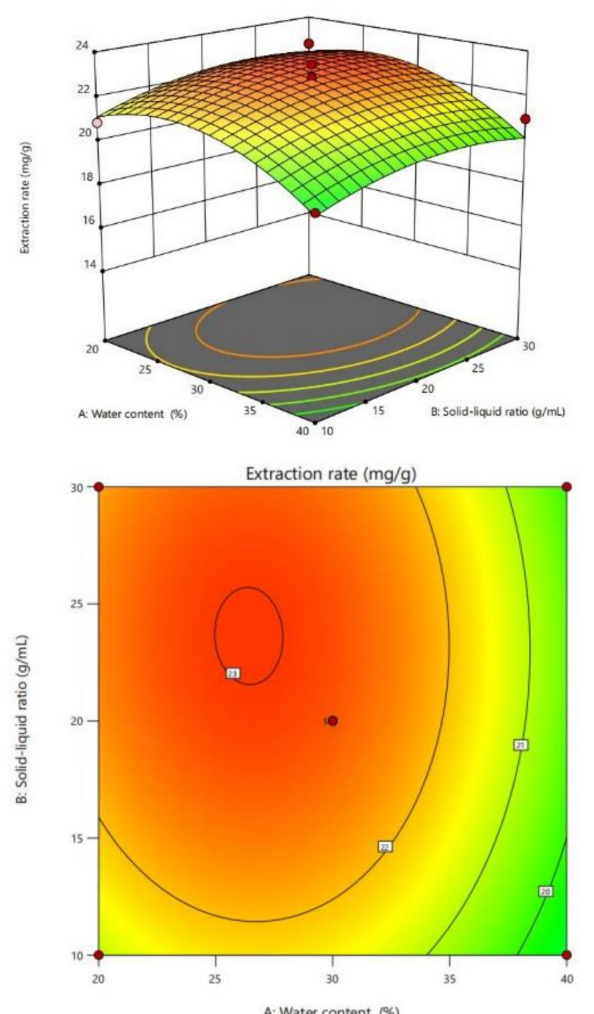

(a)
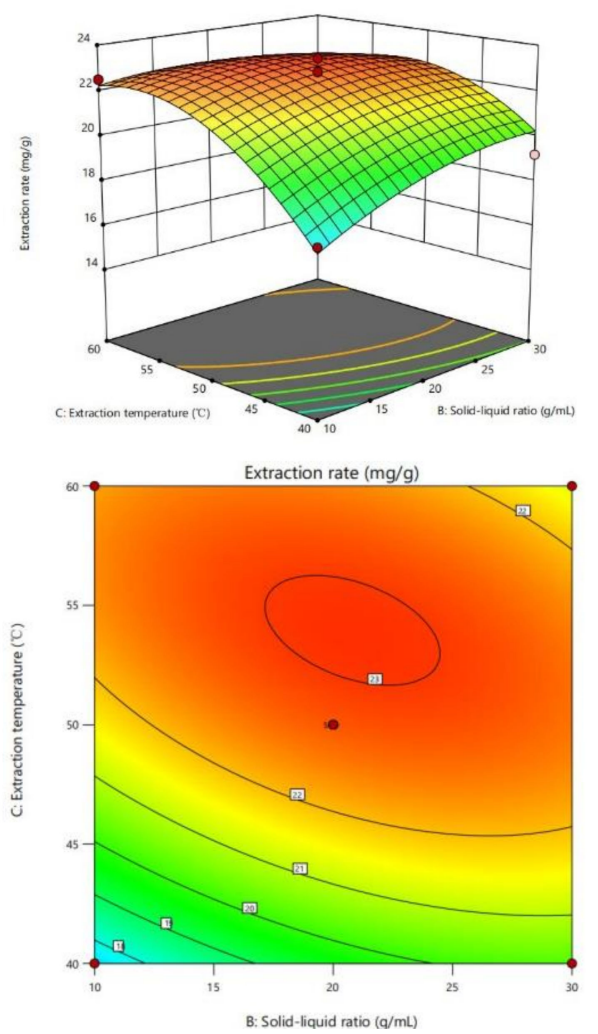

(d)
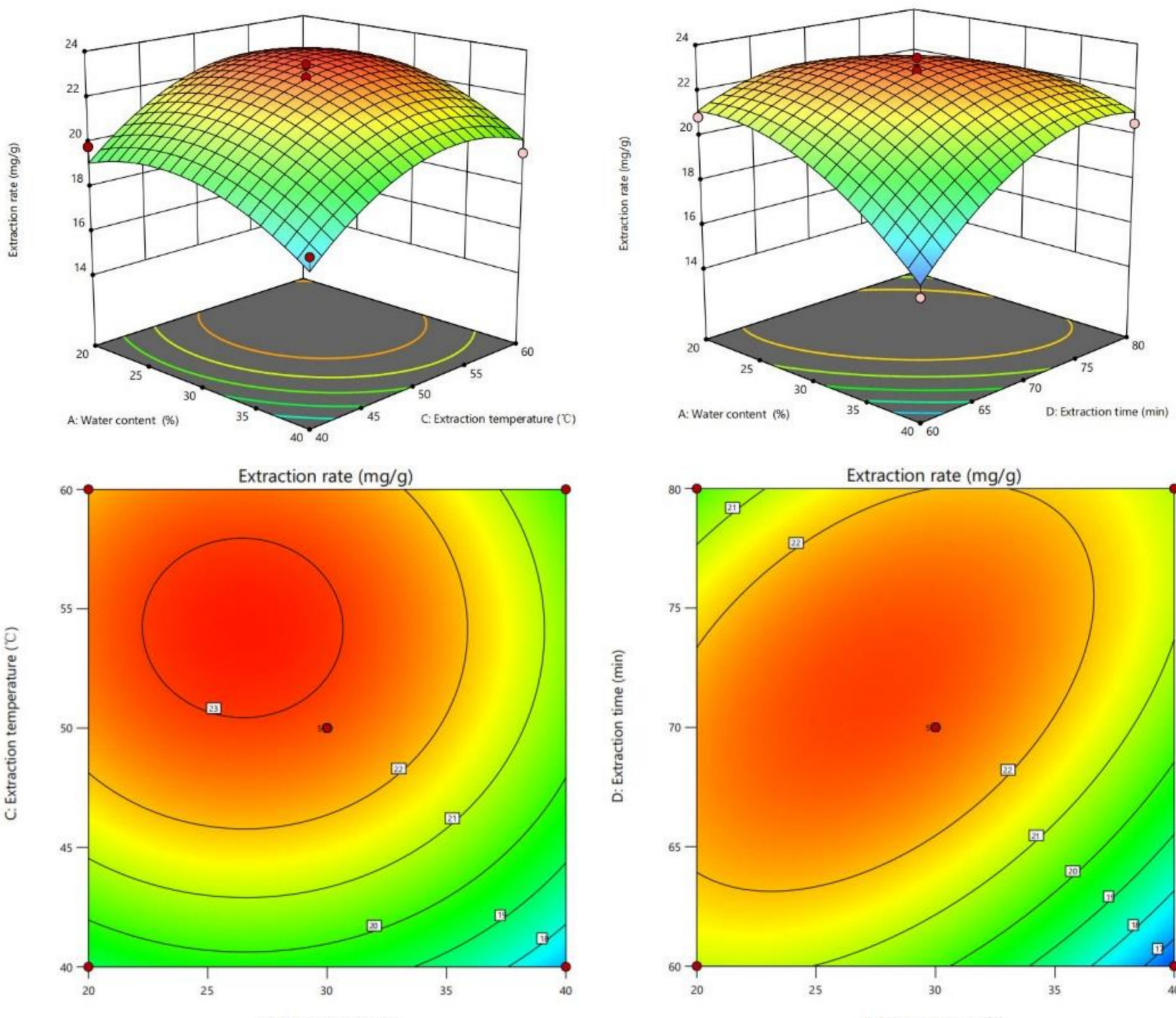

(b)

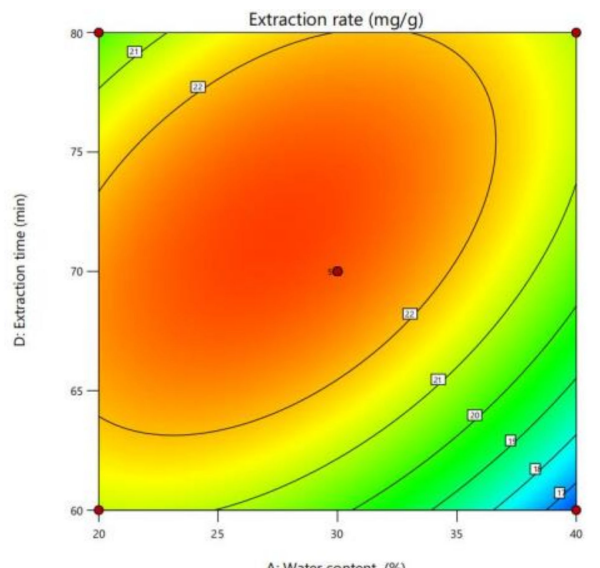

(c)
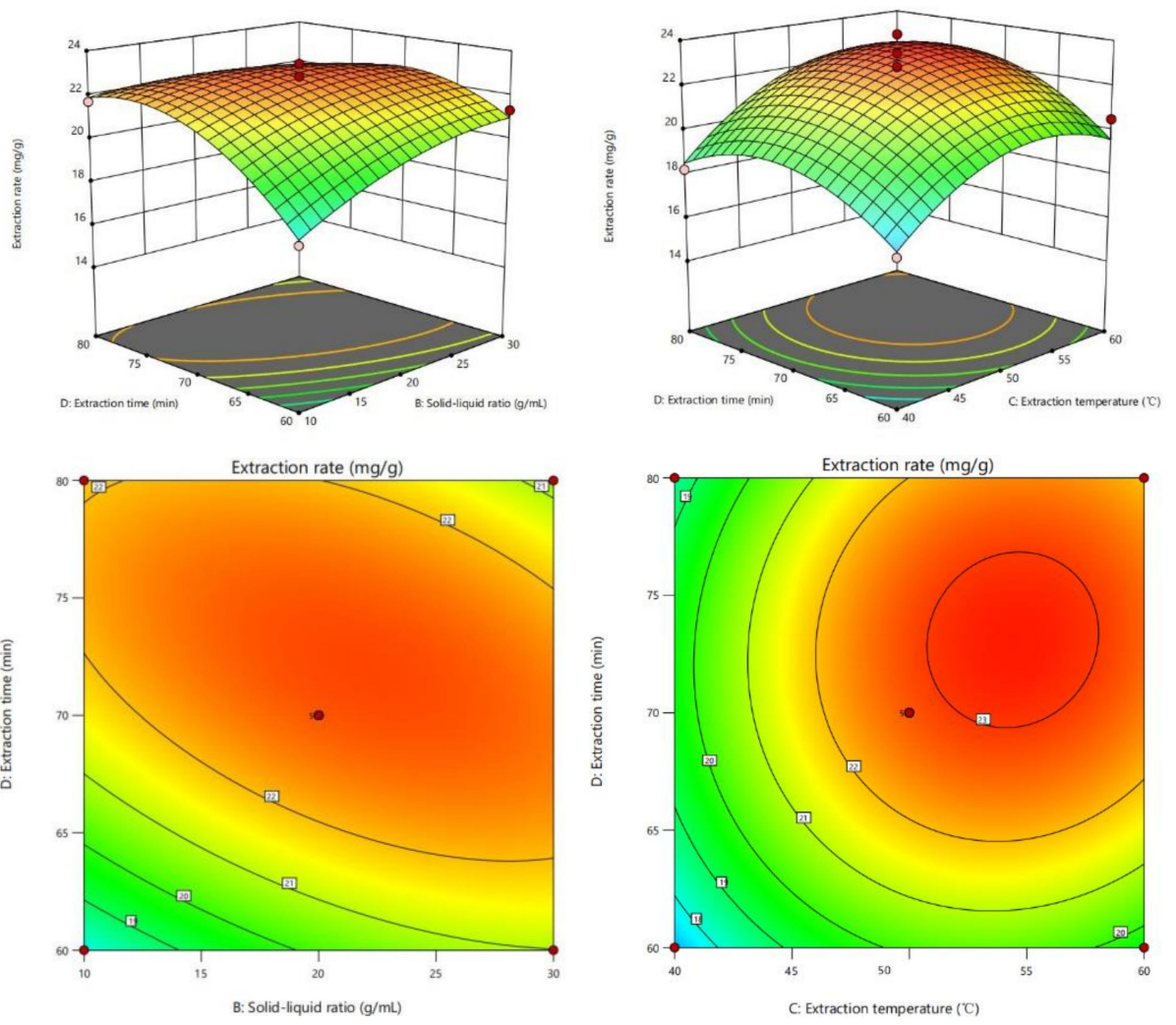

(e)

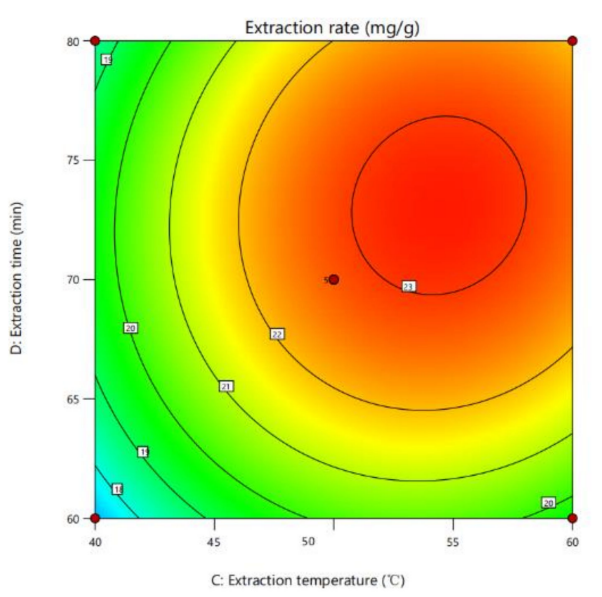

(f)

Figure 4. 3D response surface plots and contour plots $(\mathbf{a}-\mathbf{f})$ of the influence of interactions of various factors on the extraction rate of AS total flavonoids. 
The yield of AS flavonoids did not significantly change with changes in the water content and solid-liquid ratio of the system (Figure 4a). The contour line was nearly circular, indicating that interactions between the water content and solid-liquid ratio have no significant effect on AS flavonoid yield. From Figure $4 b, f$, it is evident that the yield of AS flavonoids increased first and then decreased with increase in water content-extraction temperature and extraction temperature-extraction time. However, the magnitude of the change was relatively small. The contour lines were round, signifying those interactions between water content and extraction temperature and those between extraction temperature and extraction time have no significant impact on AS flavonoid yield. In chart 4c, the extraction rate of total flavonoids increased with increasing water content and decreasing extraction time and the slope of the curved surface was relatively large. The contour line was elliptical, revealing that the mutual effects between the two have a remarkable impact on AS flavonoid yield. Response surface curves formed by extraction temperature/solidliquid ratio and extraction time/solid-liquid ratio were steep, as shown in Figure 4d,e. Simultaneously, their contour lines were elliptical and relatively tight, indicating significant interactions between extraction temperature/solid-liquid ratio and extraction time/solidliquid ratio. Notably, these findings correspond to analysis of variance data in Table 3.

\subsubsection{Model Verification and Method Comparison}

According to the model equation fitting prediction combined with the above single factor test results (Gly:La = 1:1, ultrasonic power $500 \mathrm{~W}$ ), the optimal extraction conditions for total flavonoids were as follows: water content $27.928 \%$, solid-liquid ratio $1: 18.103 \mathrm{~g} \cdot \mathrm{mL}^{-1}$, extraction temperature $54.902{ }^{\circ} \mathrm{C}$, and extraction time $72.869 \mathrm{~min}$. Under these conditions, the extraction rate of total flavonoids was predicted to be $23.318 \mathrm{mg} \cdot \mathrm{g}^{-1}$. Taking into account the actual operation, the conditions were adjusted as follows: water content $28 \%$, solid-liquid ratio $1: 18 \mathrm{~g} \cdot \mathrm{mL}^{-1}$, extraction temperature $55^{\circ} \mathrm{C}$, and extraction time $73 \mathrm{~min}$. Parallel extraction under these conditions was performed three times. The verification test revealed an average extraction rate of AS total flavonoids of $23.926 \pm 0.128 \mathrm{mg} \cdot \mathrm{g}^{-1}$, which is extremely close to the predicted value, and a relative error of less than $2.62 \%$. At the same time, the extraction rate of AS flavonoids extracted by the same power ultrasonic-assisted ethanol method (ethanol concentration $75 \%$, solid-liquid ratio $1: 18 \mathrm{~g} \cdot \mathrm{mL}^{-1}$, extraction temperature $55^{\circ} \mathrm{C}$, and extraction time $73 \mathrm{~min}$ ) was tested. Our results showed that the extraction rate using the DES method was $40.7 \%$ higher than ultrasonic-assisted ethanol extraction method $\left(17.009 \pm 0.216 \mathrm{mg} \cdot \mathrm{g}^{-1}\right)(p<0.0001)$, clearly demonstrating highly improved extraction potential.

\subsection{SEM Observation of AS Powder Microstructure}

We further explored the relationship between the degrees of rupture of plant cells with different extraction methods. To this end, the microstructure of AS powder before and after treatment was examined via SEM (Figure 5, $\times 2000$ magnification). Cells of the powdered form before extraction (Figure 5a) were intact, the cell wall surface was mostly smooth, and adjacent pores of the cell wall were closely arranged. The texture structure was clearly detectable with no trace of damage. However, all extraction methods induce a certain degree of damage to AS cells. After ultrasonic-assisted ethanol treatment (Figure 5b), the cell wall of the sample became rough and small ridges and wrinkles appeared on the tissue surface. Following application of ultrasonic-assisted DES treatment (Figure 5c), cells showed complete rupture and collapse. The tissue surface was obviously damaged, and we observed the appearance of pores. Adjacent pores are loosely arranged, and more irregular fragments were evident. These findings clearly indicate that DESs breaks down cellulose in the cell wall [52]. Accordingly, we propose the degree of rupture of AS cells is positively correlated with the extraction rate of total flavonoids, consistent with the measurement result of extraction rate. In addition, the effects of different screens (40,60, 80, 100 mesh) on the extraction of flavonoids from AS powder by UA-DES were preliminarily studied. The results showed that the extraction rate at 40 mesh was slightly lower, and there was 
almost no difference in the extraction rates of other items. In addition, if the particle size of the powder is too small, it is not convenient to separate it from the crude extract, therefore 60 mesh Acanthopanax powder was selected for follow-up test. In addition, SEM has a large scanning range, thus, in principle, from $1 \mathrm{~nm}$ to $\mathrm{mm}$ can be used for particle size analysis. We consider that the size of the sample particles does not affect the fine structures observed under the SEM because the structures presented are small enough.

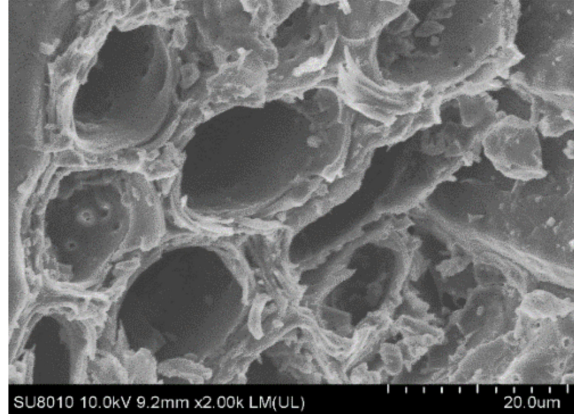

(a)

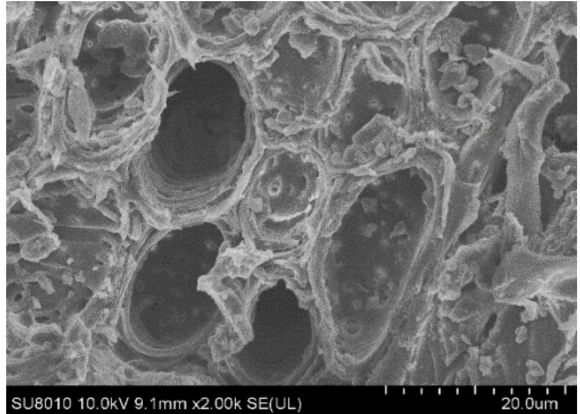

(b)

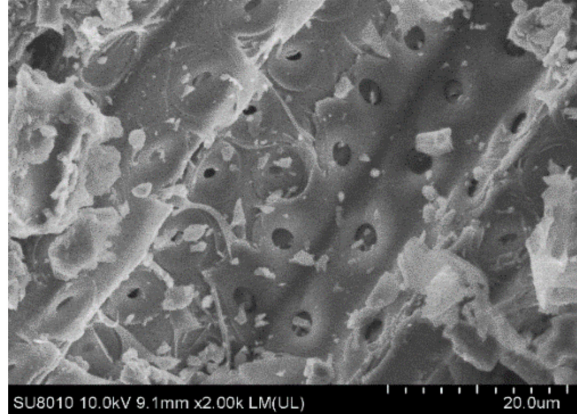

(c)

Figure 5. SEM images of AS powder (a) before processing and after extraction with (b) ultrasonicassisted ethanol and (c) ultrasonic-assisted DES.

\subsection{Recovery of Total Flavonoids and Reusability of DES}

The AS flavonoids must be effectively recovered and purified from DES extraction solvent. The documented recovery methods include macroporous resin, solid phase extraction [53], and supercritical carbon dioxide [54]. In the current research, the macroporous resin enrichment method was used to recover total flavonoids from DES extraction solvent. The macroporous resin enrichment method is simple to operate and low in cost. However, limited research date has evaluated its utility in recovery of AS flavonoids. Upon enrichment of the target component with organic extraction solution, it is necessary to remove the highly concentrated organic solvent and dilute it with water before further use in the resin adsorption and desorption steps. DESs which has been diluted with water can be directly used for resin enrichment. The hydrogen bond in DES is an important factor in target component extraction and the water content affects hydrogen bond formation between HBA and HBD. In addition, viscosity of DESs is relatively high, which leads to certain degree of effect on adsorption during the enrichment process. To achieve high-efficiency adsorption of flavonoids by the resin, earlier literature was used as a reference [55] in order to dilute the crude DES flavonoids solution to the certain concentration for subsequent experiments. Macroporous resin enrichment of total flavonoids from the extract and recovery of DES experiments were carried out at room temperature.

\subsubsection{Screening for the Resin}

In this study, the resin was selected by comparing total recovery rates of AS flavonoids in DESs using four macroporous resin types. Adsorption of macroporous resin is affected by its physical properties [56]. For example, larger specific surface area and average pore size are associated with stronger adsorption. When the polarity of the resin is similar to that of adsorbate, high recovery capacity is achieved. This involves the "like solvent like" principle [57]. The physical properties of the four resins and recovery data are presented in are shown in Table 4 . AB-8 macroporous resin had the best recovery effect on total flavonoids (68.95 $\pm 0.074 \%)$, followed by HPD600 (56.54 $\pm 0.066 \%)$, which was slightly higher than S-8 (55.85 $\pm 0.181 \%)$ and D101 resin (55.76 $\pm 0.222 \%)$. The total adsorption rate of AB-8 resin $(77.10 \pm 0.254 \%)$ was significantly higher $(p<0.0001)$ compared with the other three resins. 
Table 4. Physical properties, total adsorption capacity and total desorption capacity of four resins at $303 \mathrm{~K}$.

\begin{tabular}{|c|c|c|c|c|c|c|}
\hline Resin Types & Polarity & $\begin{array}{l}\text { Specific Surface } \\
\text { Area }\left(\mathrm{m}^{2} \cdot \mathrm{g}^{-1}\right)\end{array}$ & $\begin{array}{l}\text { Average Pore } \\
\text { Diameter/A }^{\circ}\end{array}$ & $\begin{array}{c}\text { Total Adsorption } \\
\text { Rate/\% }\end{array}$ & $\begin{array}{c}\text { Total Desorption } \\
\text { Rate/\% }\end{array}$ & $\begin{array}{l}\text { Recovery } \\
\text { Rate/\% }\end{array}$ \\
\hline D101 & Non-polar & $500-550$ & 90-100 & $66.46 \pm 0.389 \mathrm{bc}$ & $83.77 \pm 0.237^{c}$ & $55.76 \pm 0.222^{\mathrm{cd}}$ \\
\hline AB-8 & $\begin{array}{l}\text { Weakly } \\
\text { polar }\end{array}$ & $480-520$ & $130-140$ & $77.10 \pm 0.254^{\mathrm{a}}$ & $89.38 \pm 0.143^{a}$ & $77.10 \pm 0.254^{a}$ \\
\hline S-8 & Polar & $100-120$ & $280-300$ & $67.90 \pm 0.111^{b}$ & $82.25 \pm 0.150^{\mathrm{d}}$ & $55.85 \pm 0.181^{c}$ \\
\hline HPD-600 & Polar & $550-600$ & 80 & $66.13 \pm 0.085^{\mathrm{cd}}$ & $85.47 \pm 0.168^{b}$ & $56.54 \pm 0.066^{b}$ \\
\hline
\end{tabular}

Note: Different letters of superscript in the same column indicate significant differences $(p<0.0001)$.

\subsubsection{Screening Eluent Solvent}

The desorption solvent is related to polarity [58], and depends on the solubility of flavonoids. The organic solvents, such as methanol, ethanol, ethyl acetate, etc., were used for the desorption of flavonoids from resin. In this study, the desorption solvent was selected from methanol, acetic acid, ethyl acetate, $50 \%$ ethanol, $75 \%$ ethanol, and absolute ethanol, as shown in Figure 6. We observed an optimal desorption effect at $75 \%$ ethanol. The total flavonoid desorption rate was $92.32 \pm 0.158 \%$. Therefore, $75 \%$ ethanol was chosen as the optimal desorption solvent. Under optimal conditions, the recovery rate of AS total flavonoids was $71.56 \pm 0.256 \%$ ( $46.8 \pm 0.515 \%$ purity), which was significantly higher relative to that with other desorption solvents $(p<0.0001)$.

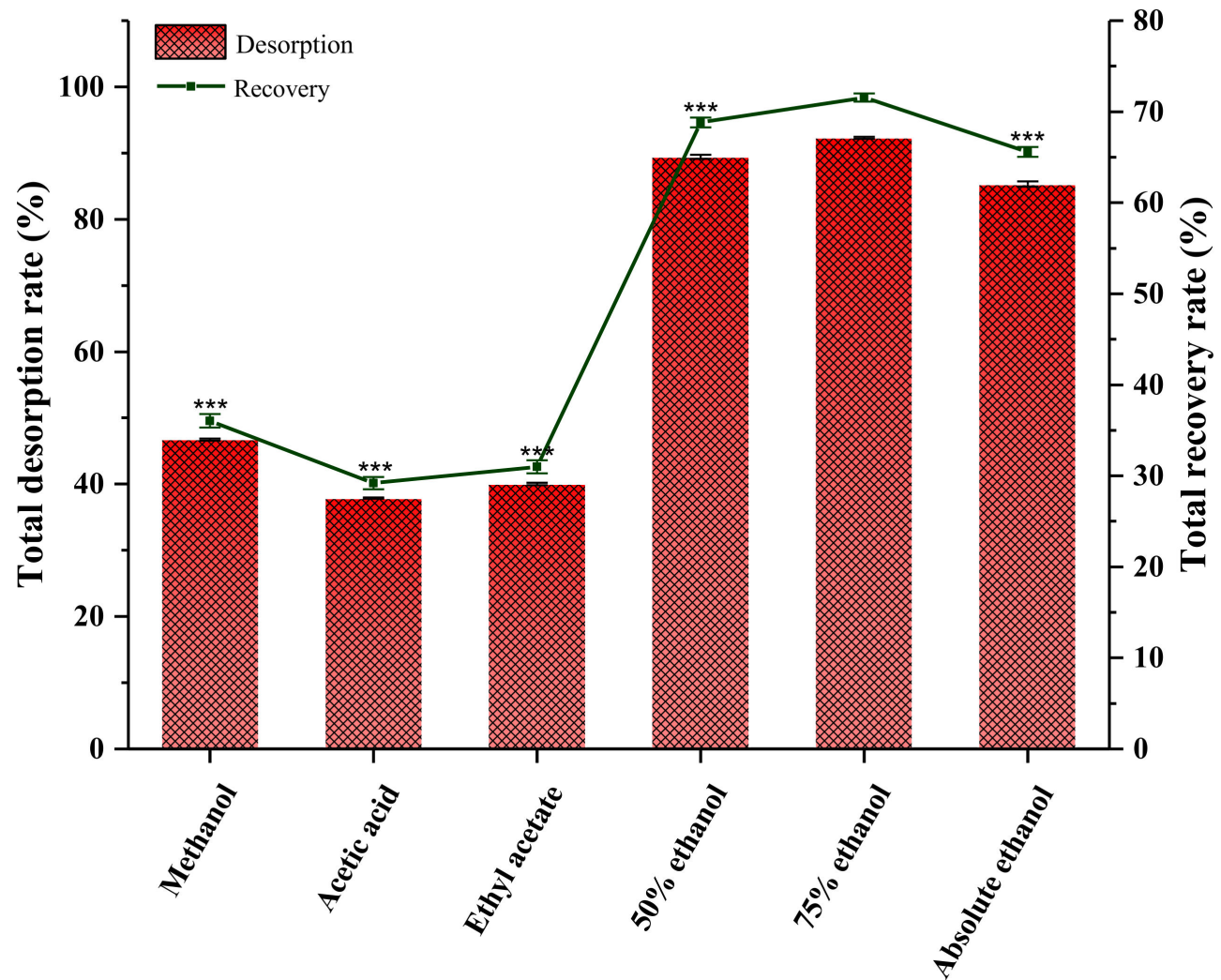

Figure 6. Comparison of total desorption and total recovery rates of AS total flavonoids with different elution solvents. Note: Values represent mean $\pm \mathrm{SD}$ of three independent experiments (compared with the total recovery rate of $75 \%$ ethanol; $\left.{ }^{* * *} p<0.0001\right)$.

\subsubsection{Reusability of DES}

Novel high-efficiency DES extraction agents can be recovered/recycled. After evaporation of water from the recovered DES in vacuum, a new extraction solvent was prepared based on the appropriate water content and further used to extract total flavonoids from 
AS. As shown in Figure 7, under optimized conditions, with increasing number of reuses of recovered DES, the content to extract target components was decreased. The extraction rates for DES upon the second and third rounds were $20.172 \pm 0.487 \mathrm{mg} \cdot \mathrm{g}^{-1}$ and $10.005 \pm 0.366 \mathrm{mg} \cdot \mathrm{g}^{-1}$, and extraction efficiencies were $84.23 \%$ and $41.78 \%$, respectively. Our results demonstrate that DESs can be reused at least twice, leading to significant cost saving.

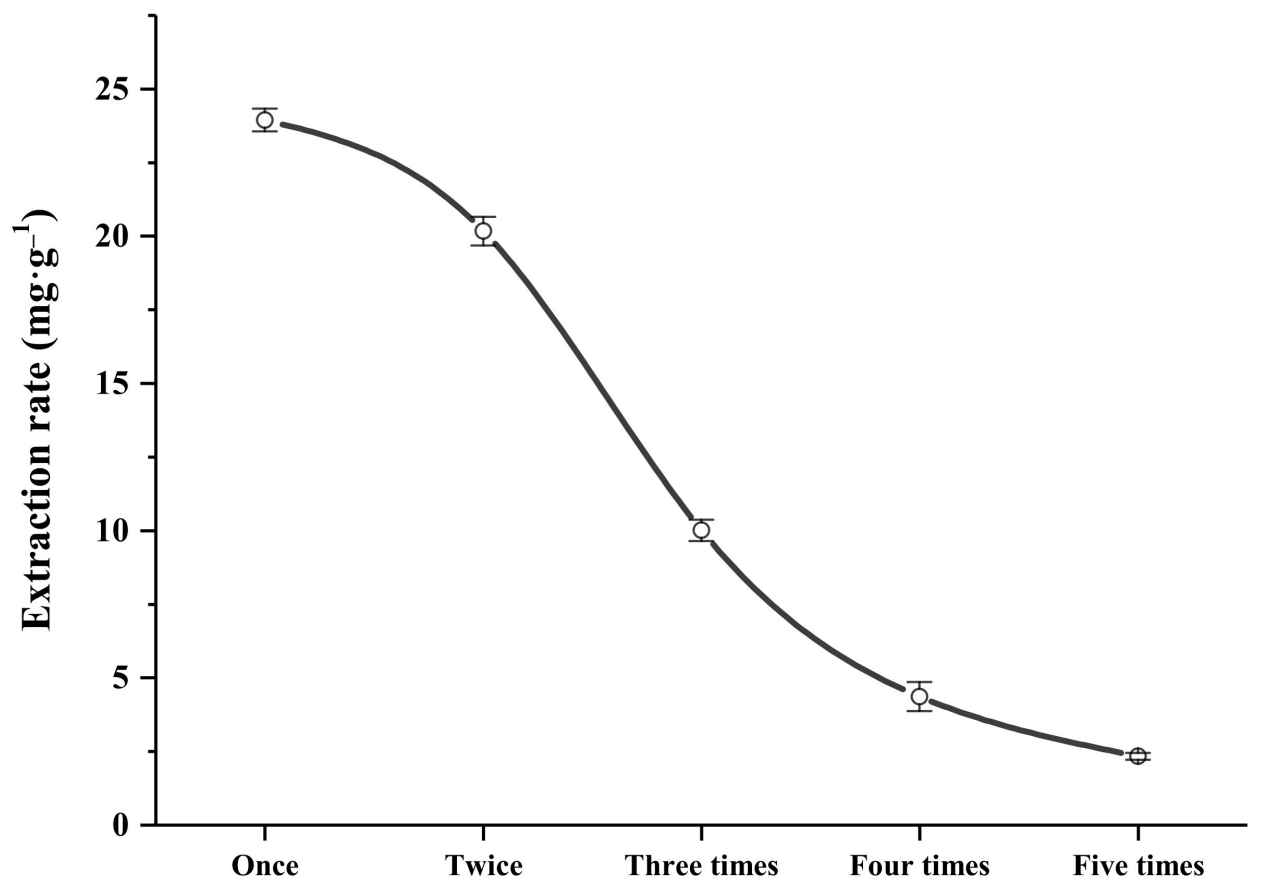

Number of reuses

Figure 7. Reusability of recycled DES.

\section{Materials and Methods}

\subsection{Reagents and Instruments}

A. senticosus was purchased from Liaocheng Limin Pharmacy (Liaocheng, China), ground into powder with a grinder (H8422, Hebei Huicai Technology Co. Ltd., Hebei, China), passed through a 60 -mesh sieve, and stored at room temperature.

Choline chloride (AR, 98\%), ethylene glycol (AR, 99.5\%), levulinic acid (AR, 99\%), 1,4-butanediol (AR, 98\%), and lactic acid (ACS, $\geq 85 \%$ ) were purchased from Shanghai Aladdin Biochemical Technology Co., Ltd. (Shanghai, China). Aluminum nitrate (AR, 99\%), citric acid (AR, $\geq 99.5 \%$ ), glycerin (AR, 99\%) and DL-malic acid (BR) were acquired from Shanghai Macklin Biochemical Co., Ltd. (Shanghai, China). Ethanol (AR, 95\%), sodium hydroxide (AR, 95\%), Methanol (AR, $\geq 99.9 \%$ ), glacial acetic acid (AR, $\geq 99.5 \%$ ), sodium nitrite $(A R, \geq 99.0 \%)$, and ethyl acetate $(A R, \geq 99.5 \%)$ were obtained from Yantai Far East Fine Chemical Co., Ltd. (Shandong, China). The four macroporous resins, D-101, HPD-600, S-8, and AB-8, were obtained from Donghong Chemical Co., Ltd. (Shanxi, China). Deionized water was prepared using a laboratory ultrapure water machine (model DBW-UP-10; Dongguan Dongbo Water Treatment Co., Ltd., Guangdong, China). All other chemicals were at least of analytical grade.

The following instruments were employed: viscometer (model Ultra DV-III; American Brookfield Co., Ltd., Middleboro, MA, USA), Fourier transform infrared spectrometer (model Thermo Nicolet iS5, Zequan International Group Shanghai Zequan Instrument Equipment Co., Ltd., Shanghai, China), pH meter (model P811; Shanghai Youke Instrument Co., Ltd., Shanghai, China), UV-visible spectrophotometer (model UV-5900; Shanghai Yuanxi Instrument Co., Ltd., Shanghai, China), centrifuges (model H1065-W; Hunan Xi- 
angyi Laboratory Instrument Development Co., Ltd., Changsha, China), ultrasonic bath (Power-Sonic SB-600DTY; Ningbo Xinzhi Bio Technology Co., Ltd., Ningbo, China), constant temperature electric water tank (model DK-8D; Shanghai Yiheng Technology Co., Ltd., Shanghai, China), constant temperature oscillator (model HZQ-F160A; Shanghai Yiheng Scientific Instrument Co., Ltd., Shanghai, China), scanning electron microscope (model SU8010, Changsha Kemei Analytical Instrument Co., Ltd., Changsha, China), and peristaltic pump driver (model BT100-2J; Baoding Lange Constant Current Pump Co., Ltd., Baoding, China).

\subsection{Experimental Methods}

\subsubsection{Preparation of DESs}

HBA and $\mathrm{HBD}$ reagents were mixed at an appropriate molar ratio, and heated in a water bath at $80{ }^{\circ} \mathrm{C}$ with constant agitation until a clear and homogeneous liquid was formed [59]. According to prediction test, Choline chloride, levulinic acid, lactic acid, malic acid, and citric acid were selected as HBA and ethylene glycol, La, 1,4-butanediol, and glycerol as HBD. Molar ratio was showed in Table 1, and eight different types of DESs were prepared.

\subsubsection{Determination of $\mathrm{pH}$ and Viscosity of DES}

The $\mathrm{pH}$ value of DES solution with $30 \%$ water content was measured using a $\mathrm{pH}$ meter at a set temperature of $30^{\circ} \mathrm{C}$. The viscosity of DES solution was measured using the Brookfield DV-III rotary viscometer. Each DES was measured in triplicate.

\subsubsection{Determination of Total Flavonoids Content}

The content of total flavonoids was determined using the $\mathrm{NaNO}_{2}-\mathrm{Al}\left(\mathrm{NO}_{3}\right)_{3}-\mathrm{NaOH}$ colorimetric method described by Feng et al. [60] with slight modifications. The rutin was used as the reference. In brief, the rutin was dissolved in DES to obtain a final concentration of $1.5 \mathrm{mg} \cdot \mathrm{mL}^{-1}$, which was used to prepare standard solutions $(0,0.25,0.5,0.75,1.0,1.25$, and $\left.1.5 \mathrm{mg} \cdot \mathrm{mL}^{-1}\right) .1 \mathrm{~mL}$ standard solutions or extract was accurately placed in a $25 \mathrm{~mL}$ volumetric flask, then, $1 \mathrm{~mL}$ of $5 \%(\mathrm{~m} / \mathrm{v}) \mathrm{NaNO}_{2}$ solution added, and shaken for $6 \mathrm{~min}$. Subsequently, addition of $1 \mathrm{~mL}$ of $10 \%(\mathrm{~m} / \mathrm{v}) \mathrm{Al}\left(\mathrm{NO}_{3}\right)_{3}$, mixed and incubated for $6 \mathrm{~min}$. Finally, $9 \mathrm{~mL}$ of $4 \% \mathrm{NaOH}$ solution was added, added $70 \%$ ethanol up to $25 \mathrm{~mL}$, with $15 \mathrm{~min}$ standing. Absorbance was measured at $510 \mathrm{~nm}$ to calculate the total flavonoid content.

\subsubsection{Extraction Process}

DES $(7 \mathrm{~mL}$ ) configured according to the corresponding molar ratio (Table 1) was added to a $20 \mathrm{~mL}$ centrifuge tube, followed by $3 \mathrm{~mL}$ water (DES water content was $30 \%$ ). The solution was heated and thoroughly mixed in a water bath at $80{ }^{\circ} \mathrm{C}$ to prepare DES extraction solvent with a solid-liquid ratio of $1: 20 \mathrm{~g} \cdot \mathrm{mL}^{-1}$. AS powder $(0.5 \mathrm{~g})$ was accurately weighed and placed in DES. Extraction rates under mechanical shaking with constant temperature oscillator-assisted extraction $\left(200,225\right.$ or $\left.250 \mathrm{r} \cdot \mathrm{min}^{-1}, 40 \mathrm{~min}, 40{ }^{\circ} \mathrm{C}\right)$ and ultrasonic-assisted extraction $\left(500 \mathrm{~W}, 40 \mathrm{~min}, 40^{\circ} \mathrm{C}\right)$ were compared.

\subsubsection{Single Factor Effects}

The effects of six single factors, specifically, Ultrasonic power $(200,300,400,500$, and $600 \mathrm{~W})$, HBA:HBD molar ratio (2:1, 1.5:1, 1:1, 1:1.5, and 1:2), DES water content $(20 \%, 30 \%$, $40 \%, 50 \%$, and $60 \%$ ), solid-liquid ratio of AS powder to DES solvent volume $(1: 10,1: 20,1: 30$, $1: 40$, and $\left.1: 50 \mathrm{~g} \cdot \mathrm{mL}^{-1}\right)$, extraction temperature $\left(30,40,50,60\right.$, and $\left.70{ }^{\circ} \mathrm{C}\right)$, and extraction time $(40,50,60,70$, and $80 \mathrm{~min})$, were evaluated on extraction yields of flavonoids.

\subsubsection{Optimization Extraction Method with RSM}

BBD was conducted by selecting the optimal levels each of the four single factors (DES water content, solid-liquid ratio, extraction temperature, and extraction time). On the basis of the experimental data, three levels of response surface experiments were conducted for 
each factor (Table 5), and the extraction rate of total flavonoid used as an evaluation index to analyze optimal combinations of the four factors.

Table 5. BBD experimental design levels.

\begin{tabular}{lccc}
\hline Levels & $\mathbf{- 1}$ & $\mathbf{0}$ & $\mathbf{1}$ \\
\hline Water content $(\%)$ & 20 & 30 & 40 \\
Solid-liquid ratio $\left(\mathrm{g} \cdot \mathrm{mL}^{-1}\right)$ & 10 & 20 & 30 \\
Extraction temperature $\left({ }^{\circ} \mathrm{C}\right)$ & 40 & 50 & 60 \\
Extraction time $(\mathrm{min})$ & 60 & 70 & 80 \\
\hline
\end{tabular}

\subsubsection{Fourier-Infrared Spectrophotometry}

FT-IR spectral measurements were performed using a Thermo Nicolet iS5 instrument. Samples were placed in the liquid pool for testing. Spectral data were recorded between 4000 and $400 \mathrm{~cm}^{-1}$ at room temperature.

\subsubsection{SEM Observation of AS Powder Microstructure}

Scanning electron microscopy (SEM) is commonly used to determine the surface morphology and structure of materials. The surface of the sample is scanned using electron beams to obtain three-dimensional spatial information [61]. The structural changes in AS powder with ultrasonic-assisted ethanol extraction were compared in this study. After drying, AS powder was adhered to the conductive glue thinly and evenly and installed on the aluminum post. After spraying a gold coating, imaging with SEM was performed at an acceleration voltage of $10 \mathrm{kV}$ and $2000 \times$ amplification.

\subsubsection{Total Flavonoid Recovery Using Macroporous Resin and Reusability of DES}

\section{Macroporous resin pretreatment}

Macroporous resin pretreatment was performed according to a previous report [62], with appropriate adjustments. Specifically, macroporous resin was soaked with absolute ethanol for $24 \mathrm{~h}$ and washed with deionized water until the alcohol was no longer present. The resin was further soaked in five times the volume of $5 \%(\mathrm{~m} / \mathrm{v}) \mathrm{NaOH}$ for $6 \mathrm{~h}$ and washed with deionized water to ensure neutrality, followed by soaking in five times the volume of $5 \%(v / v)$ HCL for $4-5 \mathrm{~h}$, and re-washing until a neutral $\mathrm{pH}$ was achieved. For storage, the resin was soaked in absolute ethanol and washed again until the alcohol was completely removed for later assay.

II. Screening for the optimal macroporous resin and desorption solvent

Columns $(16 \mathrm{~mm} \times 40 \mathrm{~cm})$ were wet packed with the pretreated macroporous resin. DES extract solution of flavonoids was diluted with water and loaded the column with a flow rate of $1 \mathrm{~mL} \cdot \mathrm{min}^{-1}$. The column was eluted with deionized water at the same speed until the ethanol was completely washed off, followed by $70 \%$ ethanol at a flow rate of 1 $\mathrm{mL} \cdot \mathrm{min}^{-1}$ for dynamic desorption. All experiments were performed in triplicate. The total flavonoid recovery rate $\left(W_{1}, \%\right)$ were calculated using followed formula [63]:

$$
\text { Total flavonoid recovery rate: } W_{1}=\frac{C_{3} \times V_{2}}{C_{1} \times V_{1}} \times 100 \%
$$

where $C_{1}$ represents the mass of flavonoids before adsorption $\left(\mathrm{mg} \cdot \mathrm{mL}^{-1}\right), C_{2}$ the mass concentration of flavonoids after adsorption $\left(\mathrm{mg} \cdot \mathrm{mL}^{-1}\right), C_{3}$ the mass concentration of flavonoids after desorption $\left(\mathrm{mg} \cdot \mathrm{mL}^{-1}\right), V_{1}$ the volume of sample liquid $(\mathrm{mL})$, and $V_{2}$ the volume of desorption liquid $(\mathrm{mL})$.

\section{Reusability of DES}

The recovered DES was evaporated for remove water and reused under optimized conditions. All experiments were repeated three times in parallel according to the above steps and the total flavonoid yield calculated each time to establish the reusability of DES. 


\subsection{Statistical Analysis}

SPSS statistical software (Version 13.0) was used to analyze data, which were expressed as mean \pm SD and examined using one-way ANOVA.

\section{Conclusions}

In present study, an eco-friendly extraction method was established and optimized to extract flavonoids from AS. The DES system composed of a Gly-La molar ratio of 1:1 achieved the best extraction effect. Under $500 \mathrm{~W}$ ultrasonic power, the optimal conditions (water content of $28 \%$, solid-liquid ratio of $1: 18 \mathrm{~g} \cdot \mathrm{mL}^{-1}$, extraction temperature of $55^{\circ} \mathrm{C}$, and extraction time of $73 \mathrm{~min}$ ), up to $23.928 \pm 0.071 \mathrm{mg} \cdot \mathrm{g}^{-1}$ flavonoid of AS was extracted, which was significantly higher compared to traditional ultrasonic assisted ethanol extraction. The macroporous resin AB-8 had high efficiency of recovered flavonoids from DES extraction liquid. Moreover, the DES can be reused twice at least. Therefore, our findings not only validate the effectiveness of DESs as a green, economical, and sustainable natural medium for extraction of flavonoids in traditional Chinese medicine, but also provide a strong theoretical foundation for their practical applications.

Author Contributions: Conceptualization, X.Z.; Data curation, X.Z.; Formal Analysis X.Z.; Funding acquisition, J.S. and X.C.; Investigation, X.Z.; Methodology, X.Z.; Project administration, X.C.; Resources, J.S.; Software, X.W.; Supervision, J.S.; Validation, X.W.; Visualization, X.C.; Writing-original draft, X.Z.; Writing-review \& editing, X.Z. and J.S. All authors have read and agreed to the published version of the manuscript.

Funding: This research was funded by the National Natural Science Foundation, grant numberss 31872515 (funder: Jianqing Su) and 32172901 (funder: Xiuling Chu).

Institutional Review Board Statement: Not applicable.

Informed Consent Statement: Not applicable.

Data Availability Statement: The study did not report any data.

Conflicts of Interest: The authors declare no conflict of interest.

\section{References}

1. Meng, Q.; Pan, J.; Liu, Y.; Chen, L.; Ren, Y. Anti-tumour effects of polysaccharide extracted from Acanthopanaxï $i \frac{1}{2}$ senticosus and cell-mediated immunity. Exp. Ther. Med. 2017, 15, 1694-1701. [CrossRef] [PubMed]

2. Qun, P.; Jianyuan, C.; Hanying, D.; Chao, W. Determination of Kaurenoic Acid in Acanthopanax trifoliatus by Ultra-High Performance Liquid Chromatography Coupled with Tandem Mass Spectrometry (UHPLC-MS/MS). Sci. Rep. 2020, 10, 1-8.

3. Ailing, J.; Yuhang, Z.; Han, G.; Zhen, Z.; Yanfei, Z.; Zhe, W.; Jinming, Z.; Bin, D.; Zhidong, Q.; Chaomei, F. A review of Acanthopanax senticosus (Rupr and Maxim.) harms: From ethnopharmacological use to modern application. J. Ethnopharmacol. 2021, 268, 113586.

4. YunQiang, Z.; YunLu, Z.; ZiKui, L. Effects of Acanthopanax senticosus supplementation on innate immunity and changes of related immune factors in healthy mice. Innate Immun. 2020, 27, 1753425920955200. [CrossRef]

5. Hongxia, L.; Jun, Q.; Changyou, S.; Pao, X. Transcriptome profiling reveal Acanthopanax senticosus improves growth performance, immunity and antioxidant capacity by regulating lipid metabolism in GIFT (Oreochromis niloticus). Comp. Biochem. Physiol.-Part D Genom. Proteom. 2021, 37, 100784.

6. Haohao, W.; Chen, C.; Ruijuan, L.; Xu, W.; Yan, Z.; Zhaowei, Y.; Enbo, C.; Hongyan, Z. Potential Myocardial Protection of 3,4-seco-Lupane Triterpenoids from Acanthopanax sessiliflorus Leaves. Chem. Biodivers. 2020, 18, e2000830.

7. Li, Q.; Luo, J.; Liu, X.; Kwon, D.; Kang, O. Eleutheroside K isolated from Acanthopanax henryi (Oliv.) Harms suppresses methicillin resistance of Staphylococcus aureus. Lett. Appl. Microbiol. 2020, 72, 669-676. [CrossRef]

8. Chunyun, W.; Hongbo, G.; Enbo, C.; Lianxue, Z.; Xiaoman, Z.; Shengbo, Z.; Nian, S.; Yan, Z. Protective effects of Acanthopanax senticosus - Ligustrum lucidum combination on bone marrow suppression induced by chemotherapy in mice. Biomed. Pharmacother. 2019, 109, 2062-2069.

9. Płotka-Wasylka, J.; Rutkowska, M.; Owczarek, K.; Tobiszewski, M.; Namiesnik, J. Extraction with environmentally friendly solvents. TrAC Trends Anal. Chem. 2017, 91, 12-25. [CrossRef]

10. Ivanović, M.; Alañón, M.E.; Arráez-Román, D.; Segura-Carretero, A. Enhanced and green extraction of bioactive compounds from Lippia citriodora by tailor-made natural deep eutectic solvents. Food Res. Int. 2018, 111, 67-76. [CrossRef] 
11. Katarzyna, T.; Marcin, K.; Edward, R. The Application of Supercritical Fluid Extraction in Phenolic Compounds Isolation from Natural Plant Materials. Molecules 2018, 23, 2625.

12. Zhou, Y.; Wu, D.; Cai, P.; Cheng, G.; Huang, C.; Pan, Y. Special Effect of Ionic Liquids on the Extraction of Flavonoid Glycosides from Chrysanthemum morifolium Ramat by Microwave Assistance. Molecules 2015, 20, 7683-7699. [CrossRef]

13. Flieger, J.; Flieger, M. Ionic Liquids Toxicity-Benefits and Threats. Int. J. Mol. Sci. 2020, 21, 6267. [CrossRef]

14. Abbott, A.P.; Capper, G.; Davies, D.L.; Munro, H.L.; Rasheed, R.K.; Tambyrajah, V. Preparation of novel, moisture-stable, Lewisacidic ionic liquids containing quaternary ammonium salts with functional side chains. Chem. Commun. 2001, 19, $2010-2011$. [CrossRef]

15. Zhuang, B.; Dou, L.-L.; Li, P.; Liu, E.-H. Deep eutectic solvents as green media for extraction of flavonoid glycosides and aglycones from Platycladi Cacumen. J. Pharm. Biomed. Anal. 2017, 134, 214-219. [CrossRef]

16. Lamei, N.; Ezoddin, M.; Abdi, K. Air assisted emulsification liquid-liquid microextraction based on deep eutectic solvent for preconcentration of methadone in water and biological samples. Talanta 2017, 165, 176-181. [CrossRef]

17. Sheldon, R.A.; Woodley, J.M. Role of Biocatalysis in Sustainable Chemistry. Chem. Rev. 2018, 118, 801-838. [CrossRef]

18. Xizhe, F.; Di, W.; Tarun, B.; Jing, X.; Yanqun, X.; Li, L.; Ligen, Z.; Lixia, Z.; Zisheng, L. Natural deep eutectic solvent enhanced pulse-ultrasonication assisted extraction as a multi-stability protective and efficient green strategy to extract anthocyanin from blueberry pomace. LWT 2021, 144, 111220.

19. Yan, H.; Jiehong, Y.; Yu, Z.; Li, Y.; Yu, H.; Haitong, W.; Chang, L. Screening, Optimization, and Bioavailability Research of Natural Deep Eutectic Solvent Extracts from Radix Pueraria. Molecules 2021, 26, 729.

20. Jianxiong, Y.; Zhenbao, Z.; Jianhua, Y.; Yang, L.; Bingcan, C.; Jiajia, R. Structure and functionality of oat protein extracted by choline chloride-dihydric alcohol deep eutectic solvent and its water binary mixtures. Food Hydrocoll. 2021, 112, 106330.

21. da Silva, D.T.; Rodrigues, R.F.; Machado, N.M.; Maurer, L.H.; Ferreira, L.F.; Somacal, S.; da Leite, V.M.; da Rocha, R.M.I.d.U.M.; Marcia, V.; Eliseu, R.; et al. Natural deep eutectic solvent (NADES)-based blueberry extracts protect against ethanol-induced gastric ulcer in rats. Food Res. Int. 2020, 138, 109718. [CrossRef] [PubMed]

22. Huang, Y.; Feng, F.; Jiang, J.; Qiao, Y.; Wu, T.; Voglmeir, J.; Chen, Z.-G. Green and efficient extraction of rutin from tartary buckwheat hull by using natural deep eutectic solvents. Food Chem. 2017, 221, 1400-1405. [CrossRef] [PubMed]

23. Jeong, K.M.; Ko, J.; Zhao, J.; Jin, Y.; Yoo, D.E.; Han, S.Y.; Lee, J. Multi-functioning deep eutectic solvents as extraction and storage media for bioactive natural products that are readily applicable to cosmetic products. J. Clean. Prod. 2017, 151, 87-95. [CrossRef]

24. Ma, Y.; Liu, M.; Tan, T.; Yan, A.; Guo, L.; Jiang, K.; Tan, C.; Wan, Y. Deep eutectic solvents used as extraction solvent for the determination of flavonoids from Camellia oleifera flowers by high-performance liquid chromatography. Phytochem. Anal. 2018, 29, 639-648. [CrossRef] [PubMed]

25. Su, E.; Yang, M.; Cao, J.; Lu, C.; Wang, J.; Cao, F. Deep eutectic solvents as green media for efficient extraction of terpene trilactones from Ginkgo biloba leaves. J. Liq. Chromatogr. Relat. Technol. 2017, 40, 385-391. [CrossRef]

26. Zhao, B.-Y.; Xu, P.; Yang, F.-X.; Wu, H.; Zong, M.-H.; Lou, W.-Y. Biocompatible Deep Eutectic Solvents Based on Choline Chloride: Characterization and Application to the Extraction of Rutin from Sophora japonica. ACS Sustain. Chem. Eng. 2015, 3, $2746-2755$. [CrossRef]

27. Duan, L.; Dou, L.-L.; Guo, L.; Li, P.; Liu, E.-H. Comprehensive Evaluation of Deep Eutectic Solvents in Extraction of Bioactive Natural Products. ACS Sustain. Chem. Eng. 2016, 4, 2405-2411. [CrossRef]

28. Wang, H.; Ma, X.; Cheng, Q.; Wang, L.; Zhang, L. Deep Eutectic Solvent-Based Ultrahigh Pressure Extraction of Baicalin from Scutellaria baicalensis Georgi. Molecules 2018, 23, 3233. [CrossRef]

29. Qin, H.; Hu, X.; Wang, J.; Cheng, H.; Chen, L.; Qi, Z. Overview of acidic deep eutectic solvents on synthesis, properties and applications. Green Energy Environ. 2020, 5, 8-21. [CrossRef]

30. Kumar, S.; Pandey, A.K. Chemistry and Biological Activities of Flavonoids: An Overview. Sci. World J. 2013, $2013,162750$. [CrossRef]

31. Hao, C.; Chen, L.; Dong, H.; Xing, W.; Xue, F.; Cheng, Y. Extraction of Flavonoids from Scutellariae Radix using UltrasoundAssisted Deep Eutectic Solvents and Evaluation of Their Anti-Inflammatory Activities. ACS Omega 2020, 5, $23140-23147$. [CrossRef]

32. Nia, N.N.; Hadjmohammadi, M.R. The application of three-phase solvent bar microextraction based on a deep eutectic solvent coupled with high-performance liquid chromatography for the determination of flavonoids from vegetable and fruit juice samples. Anal. Methods 2019, 11, 5134-5141. [CrossRef]

33. Bubalo, M.C.; Ćurko, N.; Tomašević, M.; Ganić, K.K.; Redovniković, I.R. Green extraction of grape skin phenolics by using deep eutectic solvents. Food Chem. 2016, 200, 159-166. [CrossRef]

34. Lu, L.; JuZhao, L.; Meng, L.; Wei, W.; YuYan, H.; Thomas, E.; HuiMei, W.; YuJie, F. Efficient extraction and preparative separation of four main isoflavonoids from Dalbergia odorifera T. Chen leaves by deep eutectic solvents-based negative pressure cavitation extraction followed by macroporous resin column chromatography. J. Chromatogr. B Anal. Technol. Biomed. Life Sci. 2016, 40-48, 1033-1034.

35. Mjalli, F.S.; Naser, J. Viscosity model for choline chloride-based deep eutectic solvents. Asia-Pac. J. Chem. Eng. 2015, 10, $273-281$. [CrossRef]

36. Ma, Y.; Wang, Q.; Zhu, T. Comparison of hydrophilic and hydrophobic deep eutectic solvents for pretreatment determination of sulfonamides from aqueous environments. Anal. Methods 2019, 11, 5901-5909. [CrossRef] 
37. Aljerf, L.; Nadra, R. Developed greener method based on MW implementation in manufacturing CNFs. Int. J. Nanomanuf. 2019, 15, 269-289. [CrossRef]

38. Socas-Rodríguez, B.; Torres-Cornejo, M.; Álvarez-Rivera, G.; Mendiola, J. Deep Eutectic Solvents for the Extraction of Bioactive Compounds from Natural Sources and Agricultural By-Products. Appl. Sci. 2021, 11, 4897. [CrossRef]

39. Smith, E.L.; Abbott, A.P.; Ryder, K.S. Deep eutectic solvents (DESs) and their applications. Chem. Rev. 2014, 114, 11060-11082. [CrossRef]

40. Kalhor, P.; Ghandi, K. Deep Eutectic Solvents for Pretreatment, Extraction, and Catalysis of Biomass and Food Waste. Molecules 2019, 24, 4012. [CrossRef]

41. Zhang, H.; Lang, J.; Lan, P.; Yang, H.; Lu, J.; Wang, Z. Study on the Dissolution Mechanism of Cellulose by ChCl-Based Deep Eutectic Solvents. Materials 2020, 13, 278. [CrossRef] [PubMed]

42. Mulia, K.; Fauzia, F.; Krisanti, E.A. Polyalcohols as Hydrogen-Bonding Donors in Choline Chloride-Based Deep Eutectic Solvents for Extraction of Xanthones from the Pericarp of Garcinia mangostana L. Molecules 2019, 24, 636. [CrossRef] [PubMed]

43. Abbott, A.P.; Capper, G.; Gray, S. Design of improved deep eutectic solvents using hole theory. Chemphyschem A Eur. J. Chem. Phys. Phys. Chem. 2006, 7, 803-806. [CrossRef] [PubMed]

44. Patil, S.S.; Pathak, A.; Rathod, V.K. Optimization and kinetic study of ultrasound assisted deep eutectic solvent based extraction: A greener route for extraction of curcuminoids from Curcuma longa. Ultrason. Sonochem. 2021, 70, 105267. [CrossRef]

45. Rozas, S.; Benito, C.; Alcalde, R.; Atilhan, M.; Aparicio, S. Insights on the water effect on deep eutectic solvents properties and structuring: The archetypical case of choline chloride + ethylene glycol. J. Mol. Liq. 2021, 344, 117717. [CrossRef]

46. Dai, Y.; Witkamp, G.-J.; Verpoorte, R.; Choi, Y.H. Tailoring properties of natural deep eutectic solvents with water to facilitate their applications. Food Chem. 2015, 187, 14-19. [CrossRef]

47. Xu, M.; Ran, L.; Chen, N.; Fan, X.; Ren, D.; Yi, L. Polarity-dependent extraction of flavonoids from citrus peel waste using a tailor-made deep eutectic solvent. Food Chem. 2019, 297, 124970. [CrossRef]

48. Gutiérrez, M.C.; Ferrer, M.L.; Mateo, C.R.; del Monte, F. Freeze-Drying of Aqueous Solutions of Deep Eutectic Solvents: A Suitable Approach to Deep Eutectic Suspensions of Self-Assembled Structures. Langmuir 2009, 25, 5509-5515. [CrossRef]

49. Ghaedi, H.; Ayoub, M.; Sufian, S.; Shariff, A.M.; Lal, B. The study on temperature dependence of viscosity and surface tension of several Phosphonium-based deep eutectic solvents. J. Mol. Liq. 2017, 241, 500-510. [CrossRef]

50. Abbott, A.P.; Harris, R.C.; Ryder, K.S. Application of Hole Theory to Define Ionic Liquids by their Transport Properties. J. Phys. Chem. B 2007, 111, 4910-4913. [CrossRef]

51. Onydinma, U.P.; Aljerf, L.; Obike, A.; Onah, O.E.; Caleb, N.J. Evaluation of Physicochemical characteristics and health risk of polycyclic aromatic hydrocarbons in borehole waters around automobile workshops in Southeastern Nigeria. Groundw. Sustain. Dev. 2021, 14, 100615. [CrossRef]

52. Li, Y.; Pan, Z.; Wang, B.; Yu, W.; Song, S.; Feng, H.; Zhao, W.; Zhang, J. Ultrasound-assisted extraction of bioactive alkaloids from Phellodendri amurensis cortex using deep eutectic solvent aqueous solutions. New J. Chem. 2020, 44, 9172-9178. [CrossRef]

53. Mansur, A.R.; Song, N.-E.; Jang, H.W.; Lim, T.-G.; Yoo, M.; Nam, T.G. Optimizing the ultrasound-assisted deep eutectic solvent extraction of flavonoids in common buckwheat sprouts. Food Chem. 2019, 293, 438-445. [CrossRef]

54. Nam, M.W.; Zhao, J.; Lee, M.S.; Jeong, J.H.; Lee, J. Enhanced extraction of bioactive natural products using tailor-made deep eutectic solvents: Application to flavonoid extraction from Flos sophorae. Green Chem. 2015, 17, 1718-1727. [CrossRef]

55. Na, G.; Peng, Z.Y.; Kun, L.H.; Ping, K.; Ming, L.Z.; Jie, F.Y. Effective extraction and recovery of linarin from Chrysanthemum indicum L. flower using deep eutectic solvents. Microchem. J. 2020, 159, 105586.

56. Dong, Y.; Zhao, M.; Sun-Waterhouse, D.; Zhuang, M.; Chen, H.; Feng, M.; Lin, L. Absorption and desorption behaviour of the flavonoids from Glycyrrhiza glabra L. leaf on macroporous adsorption resins. Food Chem. 2015, 168, 538-545. [CrossRef]

57. Hou, M.; Hu, W.; Xiu, Z.; Shi, Y.; Hao, K.; Cao, D.; Guan, Y.; Yin, H. Efficient enrichment of total flavonoids from Pteris ensiformis Burm. extracts by macroporous adsorption resins and in vitro evaluation of antioxidant and antiproliferative activities. J. Chromatogr. B 2020, 1138, 121960. [CrossRef]

58. Zeng, J.; Shang, X.; Zhang, P.; Wang, H.; Gu, Y.; Tan, J.-N. Combined Use of Deep Eutectic Solvents, Macroporous Resins, and Preparative Liquid Chromatography for the Isolation and Purification of Flavonoids and 20-Hydroxyecdysone from Chenopodium quinoa Willd. Biomolecules 2019, 9, 776. [CrossRef]

59. Tang, B.; Park, H.E.; Row, K.H. Simultaneous Extraction of Flavonoids from Chamaecyparis obtusa Using Deep Eutectic Solvents as Additives of Conventional Extractions Solvents. J. Chromatogr. Sci. 2014, 53, 836-840. [CrossRef]

60. Feng, S.; Luo, Z.; Zhang, Y.; Zhong, Z.; Lu, B. Phytochemical contents and antioxidant capacities of different parts of two sugarcane (Saccharum officinarum L.) cultivars. Food Chem. 2014, 151, 452-458. [CrossRef]

61. Zhu, Y.; Yang, L.; Zhang, C.; Tian, Y.; Zhang, F.; Li, X. Structural and functional analyses of three purified polysaccharides isolated from Chinese Huaishan-yams. Int. J. Biol. Macromol. 2018, 120, 693-701. [CrossRef] [PubMed]

62. Bao, J.; Cai, Y.; Sun, M.; Wang, G.; Corke, H. Anthocyanins, Flavonols, and Free Radical Scavenging Activity of Chinese Bayberry (Myrica rubra) Extracts and Their Color Properties and Stability. J. Agric. Food Chem. 2005, 53, 2327-2332. [CrossRef] [PubMed]

63. Yang, Q.; Zhao, M.; Lin, L. Adsorption and desorption characteristics of adlay bran free phenolics on macroporous resins. Food Chem. 2016, 194, 900-907. [CrossRef] [PubMed] 